\title{
¿COMPLEMENTO DIRECTO O SUJETO CON LAS FORMAS UNIPERSONALES DE HABER?
}

Se discute sobre la función sintáctica del sustantivo, pronombre u otro elemento sustantivado, directamente pospuesto o antepuesto a cualquiera de las formas unipersonales (3. ${ }^{a}$ pers. de sing.) o impersonales (infinitivo, gerundio) del verbo haber. ¿Cuál es el oficio sintáctico de personas en la frase: "Hubo personas (o «Personas hubo») que respondieron negativamente»? ¿Se trata del sujeto o del complemento (objeto) directo de hubo?

1. Muchos y muy autorizados gramáticos, p. ej. Bello, Cuervo, Lenz, la $G R A E$, Gili Gaya, M. Seco, piensan que estamos ante un complemento directo.

\subsection{Bello explica:}

El de más uso entre los verbos impersonales es haber, aplicado a significar indirectamente la existencia de una cosa, que se pone en acusativo: «Hubo fiestas», «Hay animales de maravillosos instintos»; frases que no se refieren jamás a un sujeto expreso. Decimos que por este medio se significa indirectamente la existencia, porque haber conserva su significado natural de tener; y si sugiere la existencia del objeto que se pone en acusativo, es porque nos lo figuramos contenido en un sujeto vago, indeterminado, cuya idea se ofrece de un modo oscuro y fugaz al entendimiento, pero no tanto que no produzca efectos gramaticales, concordando con el verbo en tercera persona de singular, y rigiendo acusativo; como si se dijese la ciudad tuvo fiestas; el mundo, la naturaleza tiene animales, etc. Que la cosa cuya 
existencia se significa está en acusativo, lo prueba la necesidad del caso complementario de acusativo, cuando la representamos con el pronombre él: «Estaba anunciado un banquete, pero no fue posible que lo hubiese»; «Se creyó que habría frutas en abundancia, y en efecto las hubo»; «Hay magnificas perspectivas en la cordillera, y no las hay menos hermosas y variadas en los valles». Si el impersonal haber significara de suyo existir, sería la mayor de todas las anomalías poner las cosas existentes en acusativo ${ }^{1 .}$

1.2. Por su parte, el Esbozo de una nueva gramática de la lengua española de la RAE, 3.5.7. $c^{2}$, refiriéndose conjuntamente a haber, hacer y ser como verbos impersonales, dice que

adoptan construcciones iguales a las de los verbos que expresan fenómenos de la naturaleza; p. ej.: Hubo fiestas, Hace calor, Es temprano, donde las palabras fiestas, calor, temprano son complemento de los verbos respectivos. El sujeto queda indeterminado, algo así como [la gente, el pueblo] tuvo fiestas; [la estación, el tiempo] hace calor; [el momento a que me refiero] es temprano.

Y en el párrafo $d$ ) añade:

Haber y hacer tienen entre sus varias acepciones la de indicar vagamente existencia o presencia, análoga a la que corresponde a los verbos ser y estar: No hay nadie; Hace mucho frío. Esta significación indeterminada explica que en algunas provincias españolas de Levante, $y$ en numerosos países hispanoamericanos, se interpreten con [sic] verbos personales y se diga Hubieron fiestas, Habian muchos soldados, Hicieron grandes heladas, concertando el verbo con su complemento plural, porque no es sentido como complemento, sino como sujeto.

1.3. En su edición de 1931, la Gramática académica (n. $284 c$ ) era más explícita; razonaba así:

Cuando decimos hubo fiesta o hace calor, parece a primera vista que los vocablos fiesta y calor son sujetos en sus respectivas oraciones; pero es porque nos desentendemos de la primitiva significación de dichos verbos y les atribuimos otra que no es la real y verdadera. Si analizamos una ora-

\footnotetext{
1 A Bello, Gramática de la lengua castellana, Caracas, 1951, pág. 225.

2 El Esbozo se limita a modificar muy ligeramente la doctrina de S. Gili GayA, Curso Superior de Sintaxis Española, 13. ed., Barcelona, Bibliograf, 1981, pág. 78. Las diferencias de algún relieve son: 1.a) donde el Esbozo dice, en c), «son complementos de los verbos respectivos», Gili Gaya tiene: «son complemento directo o atributo de los verbos respectivos», especificando así la noción genérica de acomplemento» y escapando al error de atribuir un complemento (directo) al verbo ser en el ejemplo Es temprano; 2. $)$ donde el Esbozo trae, en $d$ ): "sse interpreten con verbos personales», en G. G. leemos: «se interpreten como verbos substantivos». La sustitución de «como» por «con» es sin duda errata del Esbozo.
} 
ción en que entre el verbo haber en una de las siete acepciones que como unipersonal tiene en nuestro Diccionario, veremos que todas ellas se reducen a la acepción primitiva de este verbo, que es la de tener ${ }^{3}$, con sujeto tácito. Así, en hubo fiesta se sobrentiende que la gente, reunida en tal o cual lugar, o el pueblo, etc., tuvo fiesta... Luego los sustantivos fiesta y calor, en los anteriores ejemplos, son complemento directo de los verbos haber y hacer. Por eso construimos el verbo en singular cuando decimos hubo toros, hubo sustos, y no hubieron toros ni hubieron sustos. $\mathrm{Y}$ por eso también, cuando se nos pregunta: ihubo heladas?, contestamos diciendo: las hubo, empleando la forma del pronombre que sabemos es de acusativo.

1.4. Manuel Seco, en su Diccionario de dudas y dificultades de la lengua española, s. v. Haber, resume muy bien esta doctrina y le añade explicaciones útiles:

2. Transitivo impersonal, con el significado de 'encontrarse'. En este uso, el indicativo presente tiene la forma especial hay: hay habitaciones libres. No es normal el empleo de haber impersonal con un sustantivo determinado, como ocurre en este ejemplo de Galdós: «hay en Madrid los grandes opticos» (Torquemada en la cruz, 27); y en éste de Aranguren: «Mundo presente, mundo real. Sobre él hay 'el otro mundo', no ya real, sino realissimus» (Crítica y meditación, 11). El verbo haber conserva en estas construcciones un resto del sentido antiguo 'tener', pero su sujeto es indeterminado; el sustantivo que lo acompaña es complemento directo.

1.5. Recientemente (22-V-82) popularizaba «El Brocense» en $A B C$, "Sábado Cultural», pág. VII, este punto de vista, al aceptar el de A. Llorente Maldonado de Guevara, expuesto en el Anuario de Letras de México, que yo no he podido ver.

2. Son menos y de menor peso científico los sustentadores de la tesis contraria, según la cual en "Hubo personas que respondieron nega-

3 Las siete acepciones aludidas son, según la 19." ed., de 1970: «4. Acaecer, ocurrir, sobrevenir. Huво una hecatombe. // 5. Verificarse, efectuarse. Ayer нuвo junta; mañana HABRÁ función. // 6. En frases de sentido afirmativo, ser necesario o conveniente aquello que expresa el verbo o cláusula a que va unido por medio de la conjunción que. Hay que pasear; hay que tener paciencia; hay que ver lo que se hace. //7. En frases de sentido negativo, ser inútil, inconveniente o imposible aquello que expresa el verbo o cláusula a que va unido con la conjunción que o sin ella. No hay que correr; nо нау diferenciar cosas tan parecidas. // 8. Estar realmente en alguna parte. HABER veinte personas en una reunión; HABER poco dinero en un bolsillo. // 9. Hallarse o existir real o figuradamente. HaY hombres sin caridad; HAY razones en apoyo de tu dictamen [...]. // 10. Denotando transcurso de tiempo, hacer. HA cinco días; poco tiempo HA; HABRA diez años». 
tivamente» personas sería el sujeto de hubo. Entre ellos están Emilio M. Mnez. Amador ${ }^{4}$ y Martín Alonso ${ }^{5}$.

2.1.1. Martínez Amador (pág. 714 a) piensa que la explicación de la $G R A E$ «es un tanto especiosa, no en cuanto al empleo del pronombre de acusativo para substituir a la palabra que acompaña al unipersonal [...], sino en cuanto al sujeto tácito que quiere sobrentenderse». Pero no aduce contra esta explicación argumentos decisivos. Admite, incluso, que en hubo fiesta puede concebirse como sujeto sobrentendido el pueblo o la gente, equivaliendo entonces la expresión impersonal a «el pueblo (o la gente) tuvo fiesta». Pero "¿qué sujeto podremos concebir -se pregunta- en 'hay días aciagos'? ¿Será el año? ¿Será la vida? Y cuando decimos: 'hay circunstancias en la vida de los hombres', ¿qué sujeto podremos imaginar?».

2.1.2. El segundo argumento de Mnez. Amador, consistente en negar el valor transitivo de haber unipersonal, queda deslucido por un error en su desarrollo. Es claro que no se puede decir, p. ej., "fiestas fueron habidas [por la gente o por el pueblo]». Pero no tiene sentido preguntar si, «para ceñirnos más a la forma impersonal, ¿no correspondería fiestas fue habida?». Que en una oración activa el verbo vaya en singular no implica que conserve el mismo número en la formulación pasiva. Decimos: "Juan comió dos manzanas", pero "Dos manzanas fueron comidas por Juan"; y, si admitimos que en hubo fiestas se puede concebir como sujeto sobrentendido la gente o el pueblo, con lo cual hubo tendria valor transitivo y fiestas sería complemento directo, tendremos que decir en la transformación pasiva: "Fueron habidas fiestas por el pueblo». Que el español actual tienda a evitar la formulación pasiva es otro tema.

2.1.3. Carece de valor el argumento de Mnez. Amador contra el razonamiento de Bello, recogido por la $G R A E$, según el cual «la cosa cuya existencia se significa [mediante el impersonal haber] está en acusativo» porque, cuando la representamos por el pronombre personal de 3: persona, usamos éste en su forma de acusativo, como en los ejs.: «Estaba anunciado un banquete, pero no fue posible que lo hubiese», "Se creyó que habría frutas en abundancia, y en efecto las hubo». Según Mnez. Amador,

4 Diccionario Gramatical, Barcelona, R. Sopena, 1954, s. v. Haber, págs. 713-15.

5 Gramática del español contemporáneo, Madrid, Guadarrama, 2.* ed., 1974, páginas 111-19. 
si esto constituye una prueba de la calidad gramatical del objeto que acompaña al verbo, con la misma razón se podría decir que es un acusativo todo predicado nominal construido con el verbo ser, pues a la pregunta: " $i$ es rico Fulano?», contestamos: «lo es» 6 .

Pero el lo que representa a un predicado nominal no es acusativo, sino nominativo neutro, procedente del lat. illud $>$ ello, $10^{7}$.

\subsubsection{Tiene más fuerza el tercer argumento de Mnez. Amador:}

Otra razón para no considerar como un acusativo la palabra que acompaña al impersonal hay, es que no puede en ningún caso tomar preposición aunque sea un nombre propio de persona o un pronombre. Por ejemplo, no podemos emplear la a preposición en frases como: «No hay amigo para amigo" (comedia); "Lo ha dicho Carlos. - No hay Carlos que valga»; "No hay quien le aguante»; " ¿Hay alguien que lo haya visto? - No hay nadie».

2.2.1. Martín Alonso trata el problema más extensa y polémicamente. "Los orígenes de la construcción de 'habere' con el sentido de 'existir' -expone- se remontan al bajo latín. Flavio Vospicio, en su Vida de Tácito, 8, 1, dice: "habet in bibliotheca Ulpia... librum elephantinum»: "hay en la biblioteca Ulpia un libro de marfil". Y en la Peregrinatio Egeriae, 1, 2, se lee: "Habebat autem de eo loco ad montem Dei forsitan quattuor millia" ${ }^{8}$.

2.2.2. A continuación trata de explicar - siguiendo a Bassols (Sintaxis histórica, II, 1, pág. 82, Madrid, 1948)- el cambio de significación de habere "tener" (transitivo) a "ser", "existir" (intransitivo). Y concluye (pág. 112): "Al asumir el verbo habere la acepción de ser, existir, el acusativo por él regido se convirtió automáticamente en sujeto lógico de la frase».

6 Curiosamente, Bello, según Mnez. Amador, parece haber previsto este argumento contrario y dedica a esta cuestión en su Gramática toda la nota octava. En ella sostiene que "también el verbo ser puede construirse con acusativo, para lo cual supone que en la misma existencia puede imaginarse una especie de actividad, una sombra de acción sobre las cualidades y modo de ser. Alega que otras lenguas ofrecen el mismo fenómeno, como en francés: «ếtes-vous Française? - Oui, ie le suis». También Lenz opina lo mismo» (MNEz. Amador, op. cit., pág. 714 b).

7 Lo constituye una homonimia gramatical, en la que confluyen por evolución fonética el masculino illum y el neutro illud.

8 Conviene observar que librum elephantinum es formalmente un acusativo, pero el neutro plural quattuor milia tanto puede ser acusativo como nominativo. Por lo demás, de la vacilación entre el acusativo y el nominativo en el relato de Egeria puede dar cierta idea este pasaje de I, 1.: \&...se montes illi... aperiebant et faciebant vallem infinitam, ingens, planissima et valde pulchram» (ed. de Prinz, cit. por V. VäÄNÄNEN, Introducción al latín vulgar, versión esp. de Manuel Carrión, Madrid, Gredos, 1968, 3.* reimpr., 1979, pág. 289). 
2.2.3. Prescindamos de pormenores expositivos que se apartan de la cuestión. Limitémonos a lo relacionado directamente con las formas unipersonales de haber.

2.2.4. En la pág. 114 destaca en letra negrita el titulillo: Sujeto ficticio de "Hubo fiestas», con el siguiente comentario:

En la frase impersonal Hubo fiestas, los gramáticos inventan a su antojo un sujeto que puede ser verdad o no serlo. De una manera ficticia y gratuita convierten la frase hubo fiestas por esta otra: el pueblo tuvo fiestas.

2.2.5. En la pág. 115, n. $^{\circ} 38$, un nuevo titulillo, también en negrita, afirma: «En la discutida fórmula 'hay frutos', la palabra 'frutos' es sujeton.

2.2.6. Toda la pág. 116 la ocupan siete argumentos contra la posición académica expuesta más arriba (1.3.). Ninguno aporta razones válidas que no estén ya en lo dicho por Martínez Amador. Se repite también el error de considerar lo como acusativo en la frase «lo es» cuando responde a la pregunta " $¿$ Es prudente Fulano?» 9 .

2.2.7. En el titulillo del n. 39 (pág. 117) se atribuye al verbo, en la expresión "hay frutos», valor interjeccional, aunque luego -apartado $a$ ) de la pág. 118- se dice que este valor es adverbial:

La tercera persona HAY no es ni singular ni plural, sino una forma adverbializada. Es el caso de ecce homines («he aqui a los hombres»). [Hay] tiene una vibración adverbial y casi interjeccional. Como el imperativo «age» (iea!) del verbo ago pasó a ser interjección, un age, sequamur lea!, sigamos. Simple elemento acompañante.

9 En conjunto, la argumentación antiacadémica de $M$. Alonso es bastante confusa, violenta y reiterativa. Quizá lo más interesante de toda la página sean los datos históricos, sobre los partidarios de su propio punto de vista, que proporciona en la nota al pie. Según ella, «El Brocense admite la existencia de un sujeto psicológico en los impersonales. Correas hace estas formas impersonales comunes a singular y pluraln. [...] «Para Benot no hay duda ninguna del haber (existir) en tercera persona, HAY, con nominativo en singular y plural». [...] «Emilio Martínez Amador razona admirablemente esta misma teoría moderna del HAY con nominativo en su Diccionario Gramatical, palabra haber». Cita, por último, como partidario de ella a Robles Dégano en su Filosofía del verbo (pág. 133). En la misma nota aparece Bello como vacilante entre las dos posturas: «Bello, aunque admite el acusativo académico, añade: 'Si el impersonal haber significa de suyo existir, sería la mayor de las anomalías poner las cosas existentes en acusativo'». Pero Bello no dice: "Si... significa», sino «Si... significara». La condición, según Bello, no se cumple y, por tanto, no hay anomalía en poner en acusativo «las cosas existentes». 
En el apartado $d$ ) insiste:

El haY como fórmula cuajada cquivale a singular y plural o por lo menos puede acompañar a cualquiera de los dos.

$Y$ en $f)$ :

HAY, como fórmula cuajada, es un hecho deponencial o funcional. El pueblo decía: ¡Viva los autobuses! ¿Por qué? Porque había convertido la frase en una especie de interjección.

Finalmente, en $g$ ):

Al descreído se le dice: Hay un Dios misericordioso. (Con el único sentido de "existew.)

2.2.8. Esta argumentación es, en parte, aprovechable. Pero no se puede atribuir a hay, en expresiones como "Hay frutos", valor adverbial ni interjeccional, por lo mismo que no se puede considerar preposición a hace en expresiones como "Hace tres años", aunque en lenguas como el alemán su equivalente sea una preposición: "Vor drei Jahren». Hace y hay son verbos; verbos unipersonales, de los que sólo se usa la 3." pers. de singular, pero en todos los tiempos y modos: hay, habia, hubo, habrá, habria, hubiera, haya... frutos; hace, hizo, hacia, hara, haria, hiciera, haga... calor (o tres años). La interjección, el adverbio y la preposición son invariables.

2.2.9. Para demostrar que "frutos" es sujeto no se puede argumentar, como Martín Alonso (pág. 113, n. 10), apoyándose en la construcción alemana es gibt en frases como Es gibt ein [sic] Mann (HAY un hombre). No se dice en alemán "Es gibt ein Gott» (nominativo; Gott sería entonces sujeto), sino «Es gibt einen Gott» (acusativo; Gott es gramaticalmente complemento directo). El verbo geben conserva plenamente el valor transitivo, y el complemento directo de es gibt puede ser singular: «Es gibt einen Gott», o plural: «Es gibt Zeiten, in denen...» («Hay tiempos en que...»). Si estas construcciones alemanas tuvieran analogía con las españolas "Hay un Dios que rige el mundo", "Hay tiempos en que la vida es dura», apoyarían el punto de vista de quienes ven en «Dios» y "tiempos" el complemento directo de hay.

3. Si hay analogía, en cambio, de estas construcciones españolas con la francesa il y a. El Grand Larousse de la Langue Française (GLLF), s. v. AVolr, separa del uso transitivo de este verbo, plenamente vigente en francés, la expresión il y a y la función auxiliar. De il y a dice: 
1. Expresa la existencia: Il y a du monde dans la cour [\&Hay gente en el pation]. Il y avait une erreur dans ce compte [«Había un error en esta cuentan]. Sirve a veces simplemente para presentar un término de la proposición: Il y a des gens qui n'ont guère le sens du ridicule [«Hay personas que apenas tienen el sentido del ridículox] [...]. 2. Expresa el tiempo transcurrido desde cierto acontecimiento o el tiempo a partir del cual dura un estado: Il est reparti il y a cinq minutes [ Partió de nuevo hace cinco minutos»] [ ...].

Según esto, 1. equivale a nuestro hay, habia, etc.; 2., a nuestro hace, hacía, etc. La analogía entre la construcción fr. il y a y la 3. pers. sing. del presente de indicativo esp. hay se extiende incluso a la morfología. J. Corominas, Diccionario Crítico Etimológico de la Lengua Castellana, vol. II, s. v. HABER, pág. 859 , explica:

Como verbo impersonal, expresivo de la mera existencia, haber se emplea desde el principio en combinación con el adverbio $y$ 'all', en todos los tiempos, a no ser que el lugar esté expresamente determinado, que entonces se omite este adverbio aun en el presente: «bien la cerca Mio Cid, que non $y$ avia art (Cid, 1204), pero «en essas sanctas aguas $a$ otra mejor costumbre* (Alex. $1306 a$ ); andando el tiempo se tendió a generalizar el uso de $y$ en el presente, aglutinándolo al verbo, y a prescindir de él en los demás tiempos.

3.1. Pero también entre los gramáticos franceses se dividen las opiniones al intentar resolver si el nombre que sigue a las expresiones il y $a$, il $y$ avait, etc., es sujeto o complemento.

3.2.1. La postura tradicional se halla claramente expuesta en el Dictionnaire de Linguistique Larousse, par Jean Dubois et autres, Paris, 1973:

Se llama construcción impersonal la frase en que el sintagma nominal sujeto está representado por un pronombre neutro de 3.a persona, il, que sustituye al sujeto de la estructura profunda de la frase (o sujeto real); este último, por su parte, es pospuesto al verbo. La frase $I l$ est arrive un malheur [ $\mathrm{Ha}$ ocurrido una desgracia»] es una construcción impersonal procedente de Un malheur est arrivé, pues el sintagma verbal est arrivé [«ha ocurrido»] tiene como sujeto aparente un pronombre «impersonal», il, y como sujeto real un malheur [«una desgracia»], situado después del sintagma verbal.

3.2.2. Este punto de vista es también el de E. Grammont y A. Hammon ${ }^{10}$. Al hablar del «sujeto real», dicen:

10 Analyse grammaticale et logique, Paris, Hachette, 1951, pág. 151. (Obra destinada a la enseñanza media). 
En el ejemplo Il tombe de la pluie [«Cae lluvia»], el pronombre il no es el verdadero sujeto. Se puede decir De la pluie tombe [omitiendo el pronombre y anteponiendo el sustantivo al verbo]. Pluie es sujeto real. Il (pron. neutro) es sólo el sujeto aparente.

\section{Refiriéndose en concreto a la expresión il y $a$, afirman que}

equivale al verbo est. Cuando digo: il y a de l'eau dans la cruche [«Hay agua en el cántaro»], eau [«agua»] no es complemento de objeto, sino sujeto real (il: sujeto aparente). La expresión citada equivale a De l'eau est dans la cruche [sintagma nominal antepuesto al verbo, con omisión del pronombre; est $=y$ a $]$.

3.2.3. El conocido autor de Le bon usage, Maurice Grevisse, sostiene en su Cours d'Analyse grammaticale " una postura más indecisa. En los verbos impersonales - dice-, como il pleut, il neige, etc.

el pronombre neutro il, SUJETO APARENTE, es un simple signo gramatical anunciador de la persona del verbo.

\section{Líneas después añade:}

Los verbos impersonales il faut, il y a, y los verbos usados impersonalmente (p. ej.: il convient, il importe, il est juste, etc.), además del sUJETO APARENTE $i l$, tienen un SUJETO REAL, que responde a la pregunta ¿qué es lo que? o ¿quién es el que? antepuesta a ellos.

La misma postura sostiene en Le bon usage ${ }^{12}$. En frases como Il convient de partir, il faut du courage, il est arrivé un malheur, analiza il como «sujeto aparente*, y lo que en cada caso sigue al verbo, como «sujeto real* o «sujeto lógico», considerando estos dos últimos términos como sinónimos. Pero seguidamente comenta:

La tradición, en esta materia, acomoda la gramática a la lógica. Parece preferible decir que, en frases como las precedentes, el pronombre il [...] es el sujeto sin más, y que este sujeto vago, especie de sujeto provisional, es completado por el segundo elemento (el pretendido «sujeto real»).

Tal es -añade en nota al pie- la opinión de G. y R. Le Bidois (Syntaxe du Français moderne, t. I, $\S \S 319,670,671$ ). "Nos adherimos a ella -manifiesta Grevisse - , pero no negamos que esta teoría pueda, en el fondo, reducirse a la teoría tradicional que distingue entre sujeto aparente y sujeto real».

11 aLivre du Maitre», Gembloux, Ed. Duculot, 6e ed., s. a., pág. 17.

12 Gembloux, J. Duculot, ge éd., 1964, § 185. 
En el § 606. 3. se refiere particularmente a la locución il y a, que se emplea con el valor del verbo être [«ser», «estar»] para señalar la existencia, o con el valor de una preposición para indicar un tiempo pasado [en el primer uso corresponde al esp. hay; en el segundo, a hace]. Esta expresión - prosigue Grevisse- se sustituye a veces, sobre todo en el estilo elevado o poético, por il est.

Pone los siguientes ejemplos:

IL Y A donc un bon et un mauvais goût (LA BR., I, 10) [«Hay, pues, un buen gusto y un mal gusto"]; IL Y A deux jours qu'il est venu [ सHace dos días que llegó»]; IL EST des noeuds secrets, IL EST des sympathies (CORN., Rodog., I, 7) [ «Hay nudos secretos, hay simpatías»]; IL EST aux bois des fleurs sauvages (A. France, Pierre Nozière, pág. 172) [ «Hay en los bosques flores silvestres"].

3.3. Entre los gramáticos que rechazan la distinción de «sujeto aparente" y "sujeto real" y atribuyen al pronombre il la función de sujeto de los verbos impersonales, se encuentran: R. R. Wagner / J. Pinchon ${ }^{13}$, G. Mauger ${ }^{14}$, Georges Galichet ${ }^{15}$, Christian Baylon / Paul Fabre ${ }^{16}$ y la Grammaire Larousse du français contemporain ${ }^{17}$.

3.3.1. Wagner / Pinchon piensan que no se puede analizar uniformemente como sujeto lo que sigue a los verbos impersonales precedidos por el pronombre $i l$. El verbo ocupa en estas construcciones el primer lugar, con lo cual se pone de relieve el proceso significado por él y queda neutralizada la función del término que le sigue. No importa que éste designe al agente, al soporte (siège) del proceso (il vient quelqu'un [aviene alguien»], il lui est né un fils [«le ha nacido un hijo»]) o algo que cualquier gramático sólo podría considerar como un complemento (il faut du pain [ «hace falta pan»]. Citan y aprueban la opinión de F. Brunot, quien, en La Pensée et la langue, propone denominar "secuencia» (séquence) «cualquier término o miembro pospuesto al verbo impersonal» ${ }^{18}$. Brunot se apoya, según Wagner / Pinchon, en

13 Grammaire du français classique et moderne, Paris, Hachette, 1962 (ouvrage couronné par l'Académie Française), éd. revue et corrigée, págs. 62-63. 1968.

14 Grammaire pratique du français d'aujourd'hui, Paris, Hachette, se éd. revue,

15 Grammaire structurale du français moderne, Paris, Libr. Hatier, 4e éd., 1971, págs. 137-141.

16 Grammaire systématique de la langue française, Vienne, Nathan-Université, 1973.

17 Ed. de 1974.

18 A F. Brunot lo cita también a este propósito, aunque imparcialmente, M. GREvisse en le bon usage. Según Grevisse, en la pág. 289 de La pensée et la langue, 
el hecho de que en francés antiguo los sustantivos, en esta posición [e. d., pospuestos a verbos impersonales], estaban, sin excepción ${ }^{19}$, en el caso objeto, prueba de que se los sentía como complementos: Il y avait un roi [ HHabía un rey»] se decía ot un rei, nunca ot uns reis.

A continuación esgrimen Wagner / Pinchon los dos argumentos en que se apoyan también los gramáticos españoles partidarios de la función de complemento directo para el sustantivo acompañante de hay:

En francés moderno - dicen- el hecho de que el verbo permanezca siempre en singular (il manque des chaises), y que la secuencia [e. d., el sustantivo o miembro de frase que sigue al verbo impersonal] esté representada siempre por un pronombre complemento (il les faut, il en faut, il en reste, il en arrive) incita a analizar sólo el pronombre il como sujeto gramatical. [...] En cuanto al sustantivo que sigue al verbo, se podrá hablar, según los casos, de agente o de soporte del proceso (il arrive trois personnes [ «llegan tres personas»], il reste du pain ["queda pan»]) o de complemento (il faut du pain [«hace falta pan*]) ${ }^{20}$.

Pero esta doctrina no parece de acuerdo con lo que ambos autores dicen en la misma obra (pág. 520), al tratar de las frases verbales con verbo de existencia, cuya definición dan así en el n. ${ }^{\circ} 607$ :

El predicado de estas frases implica un verbo como: être [«ser» o «estar»], exister [aexistir»] y avoir [«haber»], se trouver [«hallarsew], mediante el cual se afirma la existencia (o la ausencia) del tema [aquello de lo que se habla].

Poco después, en el n..$^{\circ}$ 609, bajo el título de "Frases ligadas» (Phrases liées), exponen:

El tema, incorporado al predicado, asume en ellas la función de sujeto ( $y$ assume la fonction de sujet) ${ }^{21}$.

Brunot propone aconsiderar como verdadero complemento de objeto las secuencias de los verbos impersonales: il faut du pain; il conviendra de vous decider [aconvendrá que os decidáis»]; il faut que vous choisissiez [«es preciso que elijáis»]; il est utile que vous le fassiez le plus tôt possible [«es útil que lo hagáis lo más pronto posible»]. Se apoya también en Brunot la Grammaire Larousse du français contemporain, cuya doctrina se expondrá luego, en 3.3.4. En esta obra (pág. 176, § 265) se aconseja «tomar como modelo la exquisita modestia de F. Brunot. El eminente gramático daba a esta función [la del sustantivo que sigue sin preposición a los verbos impersonales] el nombre de 'dependencia o secuencia (dépendance ou séquence) de los verbos impersonales', y añadía maliciosamente: 'Estas palabras tienen una ventaja muy grande: no significan nada'».

19 Esto es falso, como veremos luego, en 3.3.5. $k$ ) y en la Adición fiNAl.

20 Bibliografía citada: R. MARTIN, «La transformation impersonnelle», Revue de Linguistique Romane, juill.-déc. 1970, págs. 377-394; D. GAATONE, «La transformation impersonnelle en français», Le français moderne, oct. 1930, págs. 390-411.

21 La cursiva es mía. 
Estas frases - añaden - presentan dos variedades de construcción:

Tipo: Un homme est là. - Un homme existe.

Tipo: Il y a un homme. - Il est un homme.

Il y aura un temps où l'on dira: quand il y avait des nations ["Habrá un tiempo en que se dirá: cuando había naciones»] (A. de Vigny).

Il y a là un cinéma et des arbres ["Hay allí un cine y árboles»] (A. Adamov).

Si en los ejemplos del segundo tipo se reconoce que el tema (un homme, un temps, des nations, un cinéma et des arbres) «asume la función de sujeto", ¿qué función se puede atribuir a il que no sea la de «sujeto aparenten?

3.3.2. G. Mauger (pág. 293) acepta la designación de «sujeto aparentex para el pronombre $i l$ antepuesto a los verbos impersonales, que «no es más que una partícula desprovista de significación personal»; pero observa que «este il cristaliza siempre al verbo en singular». Debe notarse igualmente «que el término llamado hace poco tiempo sujeto real ya no se siente como tal, y que su construcción es la de un objeto» ${ }^{22}$. Entre los ejemplos figura Il y a du monde ["Hay gente»].

3.3.3. Baylon / Fabre (págs. 163-64) distinguen dos grupos de verbos impersonales: a) impersonales por naturaleza, como pleuvoir [«llover»], neiger [ "nevar»], faire nuit [«hacerse de noche»], etc., junto con los presentativos il est, il y $a, \mathrm{y} b$ ) los impersonales por el uso, como manquer en la construcción il manque deux pages [«faltan dos páginas»]. Los verbos impersonales del grupo $a$ )

tienen como sujeto gramatical el pronombre il invariable, que representa lo que G. Moignet llama «la persona de universo» («Personne humaine et personne d'univers», en Travaux de linguistique et de littérature de l'université de Strasbourg, págs. 192-202).

Llamar «sujeto aparente» a este sujeto gramatical, que es, según estos autores, el verdadero sujeto, puesto que impone su ley al verbo fijándolo en el singular, «tiene el inconveniente de hacer pasar la sintaxis al segundo plano». Así, pues -concluyen-,

se llamará sujeto al sujeto gramatical [e. d., al pron. il], y se llamará régimen (a falta de un término mejor, pues esta función particular no es nombrada por los gramáticos) a lo que se llama con linda uniformidad sujeto, complemento o sujeto real.

22 El objeto se pone en francés normalmente después del verbo. 
3.3.4. La Grammaire Larousse du français contemporain, refiriéndose a Il y a (pág. 85, n. ${ }^{\circ} 123$ ), destaca el "carácter demostrativo de este presentativo», sobre todo cuando está reforzado por là, y dice que «afirma la existencia de un hecho desconocido por el oyente o lector». Seguidamente, en el n. ${ }^{\circ} 124$, dice de il est que, "fuera de las locuciones il est temps, il est dur, etc., este presentativo sólo se emplea corrientemente para indicar la hora: il est minuit, deux heures». Pero -añade- ala lengua de los cuentos lo emplea generalmente en imperfecto, y la lengua de los periódicos y de la literatura en presente, como sustituto de il y a».

En la pág. 176, el § 265 lleva como título la pregunta ¿Se puede hablar de "sujeto real»? Entre las frases analizadas a continuación figuran Partout où il y a misère, il y a souffrance. Censura como "designación extravagante" (appellation bizarre) la de "sujeto real", que aplicarían a misère y souffrance "ciertos gramáticos preocupados por la pedagogía», y dice que tal designación «descuida el aspecto formal de la definición del sujeto". Acepta la postura de F. Brunot, ya expuesta en el n. ${ }^{\circ}$ 3.3.1.

3.3.5. De los gramáticos citados es G. Galichet el que trata la cuestión con más detalle. Para facilitar la comprensión y discusión de su doctrina, la dividiré con letras en varios apartados.

a) Comienza explicando la función del sujeto, que aparece acuando se considera al ser a través del proceso, manifestando por medio de él su existencia, ya lo produzca, ya lo sufra, ya se halle en tal o cual estadox. Se refiere con esto al sujeto de la oración activa: Les enfants jouaient [ «los niños jugaban"], al de la oración pasiva: Les hommes étaient attirés par la lumière et le bruit [ "los hombres eran atraídos por la luz y el ruido"] y al de los verbos de existencia y estado: Miraut est beaucoup plus fort que Jacqueline [ $\propto \mathrm{M}$. es mucho más fuerte que J.»].

b) De aquí deduce que el agente de la acción no coincide necesariamente con el sujeto. No coincide, por ejemplo, en las oraciones pasivas: en «Los hombres eran atraídos por la luz y el ruido», el sujeto es «los hombres», mientras que el agente, aquí los agentes, es decir, los que ejecutan la acción expresada por el verbo, la acción de «atraer», son «la luz y el ruido". El sujeto de las oraciones pasivas es el objeto o complemento directo de las oraciones activas correspondientes: aLa luz y el ruido atraían a los hombres .

c) Trata luego "la famosa cuestión" del «sujeto aparente» y del «sujeto real». "La mayoría de los gramáticos -expone- analizan en la frase: «Il pleut des balles»: «il", sujeto aparente; «balles», sujeto real de "pleut». "Esta distinción -añade- nos parece especiosa; además, se LXIII, $1.0 \cdot 2.0-4$ 
basa en una confusión». Según Galichet, la construcción impersonal corresponde al siguiente mecanismo psicológico:

Se utiliza esta construcción sobre todo para poner de relieve la acción, relegando así al agente al segundo plano o incluso eliminándolo del todo.

A continuación afirma como cierto lo que precisamente se discute:

Con este giro particular, lo que en la construcción sintáctica habitual habría sido normalmente sujeto, deja de serlo.

Aduce, sin embargo, dos pruebas; una, común a todos los que niegan la existencia del "sujeto real» frente al "sujeto aparente»: en la construcción impersonal, el llamado "sujeto real» no rige la concordancia del verbo; así, en el ejemplo il pleut des balles, balles está en plural, y pleut, en singular. Es el llamado «sujeto aparente», $i l$, el que impone el singular al verbo. La segunda prueba carece de valor. Según Galichet,

cuando el pretendido «sujeto real» es una oración entera iniciada por "que», la modalidad del verbo contenido en ella viene impuesta con frecuencia por el verbo impersonal: Cf. «Il est sûr qu'elle viendra» [«Es seguro que vendrá»] frente a "Il est douteux qu'elle vienne» [«Es dudoso que venga»].

La modalidad de elle viendra (indicativo) y la de elle vienne (subjuntivo) no depende del verbo impersonal, il est, sino del predicado que acompaña a éste: sûr en la primera frase, douteux en la segunda. Lo mismo sucede en las oraciones esp. equivalentes, donde no hay construcción impersonal, pero están los predicados seguro, que rige indicativo en oraciones afirmativas, y dudoso, que exige el subjuntivo.

d) Intenta a continuación demostrar que el pron. impersonal it es el unico sujeto en las construcciones de este tipo. La dificultad causada por el hecho de que este pronombre no representa nada preciso se resuelve, según Galichet, observando, de acuerdo con Sechehaye, que

tal sujeto psicológico puede ser un dato más complejo que una idea de cosa o persona, por ej. un hecho, algo que sucede, o bien una situación en el tiempo o en el espacio determinada de algún modo, pero en sí misma vacía de representación precisa. Esta representación puede incluso reducirse a la idea totalmente vaga e inexpresable de un ambiente (une ambiance) cualquiera. Es lo que ocurre con el verbo impersonal latino pluit $=$ il pleut [alluevew].

e) Galichet aplica luego esta doctrina a la frase de P. Valéry: «Il court sur La Fontaine une rumeur de paresse et de rêveriew. Según él, il expresa justo el ambiente del que habla Sechehaye. Y rumeur de pa- 
resse et de rêverie "designa de algún modo al agente que crea este ambiente. Esta expresión completa a il court; aporta una determinación indispensable. Diremos que es un complemento de agente» (pág. 139). (Para evitar toda confusión - puntualiza en nota al pie de la páginaconvendría llamarlo "complemento de agente del verbo impersonal en voz activa», porque hay también complementos de agente del verbo impersonal en voz pasiva; ej.: "Il fut décidé par l'Assemblée que l'on tiendrait séance sans désemparer» [«Fue decidido por la Asamblea que se celebraría sesión ininterrumpida»].)

f) Antes de seguir con la exposición de Galichet, digamos que, si es cierto que el agente de la acción no coincide necesariamente con el sujeto (cfr. supra, $b$ ), también lo es que esta coincidencia se da siempre en las oraciones activas cuando el sujeto produce la acción expresada por el verbo. Y entonces, cuando el agente coincide con el sujeto, la designación de "complemento agente», aunque se le añada la determinación "de voz activa», resulta inevitablemente confusa. El "complemento agente» distinto del sujeto sólo se da en la voz pasiva. Y, si admitiésemos que une rumeur de paresse et de rêverie "completa a il court» (por lo cual se le da el nombre de "complemento", pues «aporta una determinación indispensable»), tendríamos que admitir lo mismo para Les enfants, que completaría a jouaient, en el primer ejemplo de a). En realidad es el verbo el que en cierto modo determina al sujeto, pues el verbo se dice o «se predica» del sujeto, no se predica el sujeto del verbo.

g) «Las más de las veces - prosigue Galichet-aquello en lo que se ve un sujeto "real» puede ser considerado como complemento de agente; o como un complemento de objeto directo del verbo. Ej.: «Il fut décidé que l'on tiendrait séance sans désemparer»; o también como una aposición a $i l . \mathrm{Ej}$.: «Il est certain que vous avez raison». La cursiva, en ambos ejemplos, es de Galichet, que destaca por este medio lo que otros gramáticos ven como sujeto "real» y que, según él, sería, en el primer ej., complemento de agente o complemento de objeto directo, y, en el segundo, aposición a il. Pero la oración subordinada del primer ejemplo: que... désemparer no puede ser complemento de agente, pues no representa a quien realiza la acción del verbo principal (el complemento agente, omitido aquí, está expreso antes, al fin de e): l'Assemblée), ni complemento de objeto directo, porque un verbo en voz pasiva no puede llevar tal complemento. Más aceptable sería, para ambos ejemplos, considerar las oraciones subordinadas puestas por Galichet en cursiva como aposición a il. Pero, en la aposición, los dos términos yuxtapuestos tienen la misma categoría gramatical, y no se puede decir del segundo que sea complemento agente ni de objeto directo del primero. No re- 
pugnaría a la gramática generativa analizar, en el primer ejemplo, il ( = que ... désemparer) fut décidé, y en el segundo: il (=que ... raison) est certain. Lo cual, en una traducción calcada, daría en esp.: «Ello (= que se celebraría sesión ininterrumpidamente) fue decidido», «Ello ( = que usted tiene razón) es cierto». Tendríamos entonces en las dos oraciones subordinadas de la estructura superficial sendas aposiciones epexegéticas o explicativas. (Claro que una buena traducción esp. prescindiría en ambos casos de "ello": "Se decidió celebrar sesión ininterrumpida», «Es cierto que tiene usted razón», con lo cual «celebrar sesión" se analizaría como sujeto o como complemento directo - según se viera en "se decidió» una pasiva refleja o una activa con sujeto indefinido-, y "que tiene usted razón", como sujeto indiscutible).

h) Admite Galichet (pág. 140) que, en algunos casos, «la naturaleza de este complemento será diferente. Por ejemplo en las construcciones del tipo: "Il est", «il y a» [esto nos interesa especialmente], es decir, con los verbos que indican la existencia [la cursiva es mía] más bien que la acción. Ej.: «Il est des hommes bavards» [«Hay hombres charlatanes"]. En estos casos, el verbo no tiene más papel que afirmar, insertándola en el tiempo, la existencia del ser, del suceso designado por el complemento. Llamaremos, pues, a éste «complemento de existencia» o «complemento existencial». Hay quienes objetan que no se puede situar entre los complementos al sujeto "real» porque la presencia de éste es necesaria para que el enunciado tenga sentido. A esto contesta Galichet que, «en la frase, todos los términos son más o menos necesarios»; lo son, con frecuencia, el complemento de objeto directo y el complemento de agente. Pero es indudable - se puede replicar a Galichet- que hay muchos enunciados completos sin objeto directo y sin complemento agente; sin ir más lejos, dos de los tres ejs. de proceso verbal aducidos por el propio Galichet en $a$ ): "Les enfants jouaient", "M. est beaucoup plus fort que J.», $y$, en general, todos los enunciados formados con verbos intransitivos. En cambio, todos estos enunciados necesitan, para tener sentido, un sujeto expreso o tácito.

i) Según Galichet, la distinción de «sujeto aparente» y «sujeto real» se basa en una confusión. Quienes afirman que en la citada frase de Valéry rumeur es "sujeto real» pueden querer decir una de estas dos cosas:

o bien entienden que rumeur designa al agente de la acción, y entonces confunden agente y sujeto; o bien afirman que rumeur etc. es sujeto gramatical del verbo, apoyándose en la frase que expresa una idea análoga: Une rumeur de paresse et de rêverie court sur La Fontaine. [...] Ahora bien, es en el tipo de frase especialmente elegido por el escritor donde hay 
que analizar las relaciones sintácticas de los elementos, y no en otro, más cómodo de analizar, sin duda, pero diferente.

A esto se puede contestar lo siguiente: $\left.1 .^{\circ}\right)$ Afirmar que, en la frase de Valéry, rumeur es "sujeto real" no es confundir el agente con el sujeto. Sabemos que, en las oraciones pasivas, el sujeto no es el agente sino el paciente de la acción. Pero también sabemos que, en las oraciones activas que tienen agente, éste se identifica siempre con el sujeto. Ahora bien, Il court sur La Fontaine une rumeur... es una oración activa. 2.) Al preferir la construcción impersonal, Valéry - como observa el propio Galichet - «ha buscado un efecto de estilo, ha querido destacar el verbo». Pero esto no implica que haya querido cambiar la función sintáctica de une rumeur etc., que sigue siendo la de agente de una oración activa $y$, por tanto, la de sujeto, incluso para quienes distinguen con toda nitidez entre ambos conceptos.

j) El último argumento de Galichet es de carácter histórico. Reconoce que, en los comienzos del fr. antiguo,

el verbo impersonal concertaba frecuentemente en número con el llamado «sujeto real». Ej.: «En cel pré avoit un rastelier où il manjoient 150 toriaux». Pero ¿cómo hablar aquí de verbo impersonal?

Efectivamente, el verbo manjoient, 3. ${ }^{\mathrm{a}}$ pers. del plural, concierta en número con 150 toriaux.

No olvidemos - advierte Galichet- que il impersonal sólo comenzaba a ser introducido en estos tipos de frases y que estas construcciones no eran más que ejemplos de la construcción, tan frecuente en fr. antiguo, de la inversión verbo-sujeto. Cf. "Vint Roland sur son cheval». El «il» -considerado largo tiempo como expletivo (se omitía incluso en los giros del tipo «il y an; se decía: «y an, e incluso «a», giros que todavia hoy hallamos en fórmulas fijas como «Mieux vaut tard que jamais» [«Más vale tarde que nunca»], «D'où vient que...» [«De donde viene que...»] - no fue considerado como un verdadero sujeto gramatical. Era entonces un verdadero "sujeto aparente».

Esta concesión es muy interesante. En los comienzos del francés, el il impersonal era, pues, expletivo, mero "sujeto aparente», que podía anteponerse al verbo cuando éste se anteponía, a su vez, al «sujeto real».

Pero -prosigue Galichet- cuando, en virtud de la «ley de posicion», el "sujeto real» fue pospuesto al verbo y ya no impuso siempre su concordancia con él, fue considerado cada vez más como un complemento. [...] Aparecía poco a poco un esquema sintáctico absolutamente nuevo sin que la construcción tradicional se modificara: es aqui sin duda donde hay que 
buscar el origen de la confusión que denunciamos y de esta distinción especiosa entre lo «aparente» y lo «real», con la cual muchos gramáticos creyeron evitar una contradicción, pero que no corresponde al sentimiento de los usuarios de la lengua.

Hay aquí dos afirmaciones subjetivas, que, en el fondo, se reducen a una: $\left.1 .{ }^{2}\right)$ el "sujeto real", al posponerse al verbo y no imponerle siempre la concordancia, fue considerado cada vez más como un complemento; 2. ${ }^{a}$ ) la distinción entre "sujeto aparente" y "sujeto real» es especiosa y no corresponde al sentimiento de los usuarios de la lengua. Todo esto habría que demostrarlo. Quien no tiene en francés la "competencia» o el "sentimiento de la lengua» de un hablante nativo carece de autoridad para contradecir a un gramático como Galichet. Pero el escepticismo frente a ambas afirmaciones se justifica por el hecho de que haya otros gramáticos que siguen defendiendo la distinción entre "sujeto aparente» y «sujeto real», y por el resultado de una pequeña encuesta realizada entre media docena de licenciados cuya lengua materna era el francés, alumnos del Instituto Universitario de Lenguas Modernas y Traductores de la Universidad Complutense de Madrid, todos los cuales analizaron, en la frase "Il y avait trois hommes dans la rue», il como "sujeto aparente» y trois hommes como "sujeto real».

k) Tampoco es exacto lo que R. L. Wagner -citado en nota por Galichet- dice en Le Français dans le Monde, n. ${ }^{\circ}$ 29, diciembre de 1946, pág. 10:

Para el francés antiguo, es patente un hecho: mientras un caso objeto se opuso a un caso sujeto, el sustantivo pospuesto a «a» o a «ot" se puso en el caso objeto: «ot un rei» y nunca «ot uns reis».

El GLLF, pág. 6337 a, muestra que, en las construcciones con avoir impersonal, el sustantivo pospuesto lleva en $\mathrm{fr}$. antiguo unas veces el caso régimen y otras el caso sujeto. Da estos dos ejemplos: Ne n'avoit si hardi home [caso régimen] dedens le cité qui as murs osast moustrer le doit (Chronique d'Ernoul, XIII ${ }^{\mathrm{e}}$ s.). - En celuy tens, avoit aucuns jeunes homes [caso sujeto] en Chipre (Philippe de Novare, XIII' s.), que traduce así al fr. moderno: "En ce temps-là, il y avait à Chypre un jeune homme». Añade que desde los primeros textos aparece también la locución y $a$ igualmente construida con el caso sujeto o con el caso régimen; las dos construcciones se muestran inmediatamente próximas en los versos 554-55 de la Vie de saint Alexis:

Nuls [c. sujeto] n'en $i$ at kin alget malendus (qui s'en aille malade), Cel [c. régimen] n'en $i$ at kin report sa dolur (qui remporte son mal). 
4. Vimos antes, n. ${ }^{\circ}$ 3.3.4., que la Gram. Larousse $d u$ fr. contemporain rechazaba la noción de «sujeto real» porque «descuida el aspecto formal de la definición del sujeto». Por su parte, Galichet achaca a los sostenedores de la distinción entre "sujeto aparente» y «sujeto real» la confusión de «sujeto» y «agente», y propone considerar el «sujeto real» como "complemento agente» o bien como "complemento de objeto». Siendo, efectivamente, las de sujeto y complemento las dos nociones discutidas en relación con los sustantivos o términos sustantivados que en fr. siguen a los verbos impersonales y en esp. acompañan inmediatamente a las formas impersonales de haber, conviene precisar los límites de ambos conceptos.

4.1. En una oración bimembre normal, compuesta de sujeto y predicado, llamamos sujeto al término que designa a la persona, cosa o entidad (concreta o abstracta) de la que decimos algo. Entendemos por predicado lo que decimos del sujeto.

4.2. El sujeto está representado por un sustantivo, un pronombre $\mathrm{u}$ otro vocablo o miembro de frase sustantivado. Son sujetos en las oraciones siguientes las palabras que van en versalitas: (1) JUAN duerme; (2) EL PERRo ladra; (3) ÉSTE es bueno; (4) AYER fue domingo; (5) SI es una conjunción. En (4) y (5), AYER (adverbio) y SI (conjunción) funcionan como sustantivos. En (1) y (2) tenemos sendos "predicados verbales», constituidos por el verbo correspondiente. En (3), (4) y (5) estamos ante los llamados "predicados nominales", constituidos por un verbo copulativo + un sustantivo o adjetivo. Ahora nos interesan los «predicados verbales».

Hay verbos que expresan una acción cuyo efecto pasa del agentesujeto a un objeto; son los llamados verbos "transitivos», p. ej., comer y tener en Juan come una manzana y Pedro tiene una idea, donde Juan y Pedro son los sujetos, y come una manzana y tiene una idea, los predicados; éstos pueden analizarse en verbo («come», «tiene») + complemento u objeto directo ( uuna manzana», "una idea»). No nos interesan ahora ni el complemento indirecto ni los distintos complementos circunstanciales.

4.3. Es válido el criterio escolar para conocer la transitividad de un verbo y el carácter de complemento $\mathrm{u}$ objeto directo del término afectado por la acción expresada por él: transformar la oración activa en pasiva; el complemento directo de la oración activa se convierte en sujeto de la pasiva, y el sujeto de la oración activa pasa a ser comple- 
mento agente de la pasiva. Ej.: activa: «Juan (suj.) come una manzana» (compl. dir.); pasiva: "Una manzana (suj.) es comida por Juan» (compl. agente).

5. Sobre estas bases podemos estudiar la naturaleza de oraciones formadas en fr. con las formas impersonales de avoir precedidas de il $y$, y en esp., con las formas unipersonales de haber. El estudio de la construcción francesa puede ayudar a comprender la construcción equivalente española.

5.1. Vimos en 3. que, según el GLLF, il y a expresa la existencia. Esto lo admiten todos los autores citados. E. Littré, Dictionnaire de la langue française, ed. de 1971, da como sinonímicas las construcciones il y a, il existe: "Avoir - dice- se usa impersonalmente con el pronombre $y$ en muchas locuciones. Il y $a$, il existe». Pone, entre otros, el siguiente ejemplo: Il y aura des vices tant qu'il y aura des hommes.

5.2. El giro fr. il y a equivale al ing. there is, que, como es notorio, introduce oraciones existenciales ${ }^{23}$. Pues bien, los traductores franceses pueden traducir there is indistintamente por il y a o il existe. He aquí dos traducciones francesas de un texto de B. Russell (The Problems of Philosophy, pág. 1):

"Is there any knowledge in the world which is so certain that no reasonable man could doubt it?"

1. "Y a-t-il au monde quelque connaissance si certaine, que nul homme raisonnable n'en puisse douter?» (J. F. Renauld, Les Problèmes de la Philosophie, Paris, Alcan, 1923, pág. 1).

2. «Existe-t-il au monde une connaissance dont la certitude soit telle qu'aucun homme raisonnable ne puisse la mettre en doute?» (Trad. de S. U. Guillemin, Petite Bibliothèque Payot, 1980, pág. 7).

$Y$ a-t-il y existe-t-il son equivalentes. Ambas expresiones, como la ing. is there, preguntan por la existencia. ¿Y a quién o a qué cosa o entidad se atribuye esta existencia por la que se pregunta? Es indudable que, en los textos citados, se pregunta por la existencia de «any knowledge», de "quelque connaissance» o de "une connaissance». En cuanto al texto inglés, nadie le negaría la condición de sujeto a knowledge. No ocurre lo mismo con connaissance en los dos textos franceses. Según vimos en 3.3.1. - 3.3.4., le negarían a este término la condición de sujeto los autores

23 Cfr. R. Quirk y otros, A Grammar of Contemporary English, London, Longman, 1972, pág. 956, n.० 14.24: «Existential sentencesi. 
que consideran auténtico sujeto gramatical el pron. il. Para ellos connaissance sería complemento (Wagner / Pinchon), dependencia, secuencia, complemento de objeto (F. Brunot), objeto (G. Mauger), régimen (Baylon / Fabre), complemento de agente, complemento directo, aposición a IL (Galichet). Pero, prescindiendo de los términos dependencia, secuencia y régimen, que, como reconocía $\mathrm{F}$. Brunot (supra, n. 18), no significan nada, ¿se puede llamar complemento o complemento de objeto al término del que se dice el predicado? (El predicado es, indudablemente, $y$ a en el primer texto francés, y existe en el segundo, como lo es is there en el texto inglés).

5.3. El obstáculo principal para que los autores franceses citados reconozcan como sujeto a connaissance está en el pron. il, que es para ellos el sujeto gramatical y, por consiguiente, el verdadero sujeto. Ven la prueba de esto en que impone su ley al verbo, fijándolo en su propio número singular, aunque el término que siga al verbo esté en plural, como en el citado ej. de Littré: "Il y aura des vices tant qu'il y aura des hommes» [Habrá vicios mientras haya hombres»].

5.4. Este mismo problema se plantea en inglés con el pron. it, que lleva el verbo en singular, is, aunque siga un término en plural: it is eight o'clock [ «son las ocho»], it is they ["Son ellos»], it is two hundred miles from Boston to New York [ "hay doscientas millas desde B. a N. Y.»], y también en alemán con el pron. es, que produce construcciones como Es ist drei Uhr ["Son las tres»], Es ist acht Tage her, seit ich gekommen bin [ "Hace ocho días que llegué»], aunque también son posibles en esta lengua construcciones con es y el verbo en plural, como Es sind noch einige Bücher da [ «Hay todavía algunos libros»].

El problema parece bien resuelto, para el inglés, en la o. c. de R. Quirk y otros, y, para el alemán, en el Lexikon der deutschen Sprachlehre del Dr. Walter Ludewig, incluido en el Deutsches Wörterbuch de G. Wahrig, págs. 49-250. En la primera de estas obras, pág. 963 , n. ${ }^{\circ} 14.36$, bajo el título de Extraposition of a clausal subject [ «Extraposición del sujeto frásico»], leemos:

El tipo más importante de extraposición es la extraposición del sujeto frásico [e. d., consistente en una frase, como: "Es seguro que Juan vendrán]. El sujeto frásico se coloca al fin de la oración, y el puesto del sujeto nominal se cubre con el pronombre anticipador it. La oración resultante contiene así dos sujetos, que podemos identificar con el sUJETo posPUESTo (la frase que es nocionalmente el sujeto de la oración) y el sUJETo ANTICIPADOR (it). 
W. Ludewig, pág. 191, «Personalpronomen», 3.2.1., dice:

Es aparece frecuentemente como precursor del sujeto auténtico, y hace posible la posición final acentuada de éste: "Es war einmal ein Müller..." [ "Había una vez un molinero...»], «Es führen viele Wege nach Rom» [«Muchos caminos llevan a Roma»] 24. Esto -observa Ludewig - se aplica especialmente cuando el sujeto es una oración subordinada [el tipo más importante de «extraposición» del sujeto frásico, según Quirk et al.]: «Es ist nicht gut, dass der Mensch allein sei» ["No es bueno que el hombre esté solo»].

5.5. La presencia en una misma oración de un sujeto pronominal anticipador del sujeto real y de este segundo sujeto pospuesto al verbo, en lenguas como el alemán, inglés y francés, no es más chocante que la aparición de un complemento pronominal en esp., fr., it. y port., antepuesto o pospuesto, en la misma oración, al verdadero complemento de su misma naturaleza (directo o indirecto). Tal complemento pronominal no acompaña al complemento real en alemán ni en inglés. Ej. de doble complemento directo en esp., fr., it. y port. ( nominal en las oraciones ing. $y$ al. correspondientes):

La victoria, puedo garantizarla.

La victoire, je peux la garantir.

La vittoria la garantisco.

$A$ vitória eu a posso garantir.

Victory, I can guarantee.

Den Sieg kann ich verbürgern.

Ejemplo de doble complemento indirecto en esp. (sin complemento pronominal en alemán):

A los dioses no pueden sucederles esas cosas.

Den Göttern können solche Dinge nicht passieren.

El complemento pronominal puede ser también anticipador del verdadero complemento:

Dale este libro a tu hermano.

24 Para mayor tranquilidad del lector, he aquí los textos originales:

"The most important type of extraposition is the extraposition of a clausal subject. The clausal subject is placed at the end of the sentence, and the nominal subject position is filled by the anticipatory pronoun $i t$. The resulting sentence thus contains two subjects, which we may identify as the POSPOSED SUBJECT (the clause which is notionally the subject of the sentence) and the ANTICIPATORY SUBJECT (it).»

«Es erscheint oft als Vorläufer des eigentlichen Subjekts und ermöglicht seine betonte Endstellung: es war einmal ein Müller...» 
5.6. Así, pues, mejor que llamar «sujeto aparente» al pron. il en las construcciones impersonales con verbos intransitivos, como $I l$ est venu trois dames, diremos que estas oraciones tienen dos sujetos: el «sujeto anticipador», il, y el "sujeto real» pospuesto: trois dames. En esta construcción, llamada impersonal, se pone de relieve el sujeto pospuesto, que en la construcción normal $-\mathrm{y}$, por tanto, estilísticamente neutra- iría antepuesto al verbo y concertando con él en número y, en determinados casos, también en género: Trois dames sont venues.

6. Queda por resolver el problema de si avoir en la construcción il y a, il y avait, etc., y haber en hay..., habia..., etc., son transitivos o intransitivos.

6.1. El verbo fr. avoir conserva con plena vigencia el valor transitivo. El GLLF, pág. $347 a-c$, distribuye en cuatro apartados generales los usos particulares, ejemplificados, en que avoir tiene dicho valor. Para abreviar, sólo se recogen aquí los títulos de los apartados generales, con un ejemplo representativo: I. EXPRESA LA POSESIÓN: Il a une maison à la campagne ["Tiene una casa en el campo»]. II. EXPRESA UNA SIMPLE RELACIÓN DE PERTENENCIA: Ces élèves ont un professeur très exigeant [«Estos alumnos tienen un profesor muy exigente»]. III. EXPRESA EL ESTADO 0 EL COMPORTAMIENTO DE UNA PERSONA: Avoir faim ["Tener hambre»]. IV. Forma NUMEROSAS LOCUCIONES: Avoir un entretien avec quelqu'un [*Tener una conversación con alguien"]. Sigue una lista de sinónimos, y a continuación, en párrafo aparte:

"Il y a loc. impers.", de la que en primer lugar se nos dice que «expresa la existencia». Es, por consiguiente, sinónimo de être y de exister, a los cuales nadie atribuiría valor transitivo. Estos verbos no pueden, por tanto, llevar un complemento de objeto directo, como no podrá llevarlo su sinónimo il y a. Nótese que en los cuatro ejemplos recién citados de uso transitivo de avoir el equivalente de traducción esp. es tener, igualmente transitivo. En los ejemplos de la locución impersonal: Il y a du monde dans la cour, Il y avait une erreur dans ce compte, la traducción requiere la locución impers. esp. hay, habia, que, como veremos seguidamente, equivale igualmente a verbos de existencia $y$, por tanto, tiene valor intransitivo.

7. En haber (auer, aver) predominaba inicialmente el valor transitivo. En el Poema de Mio Cid ${ }^{25}$ abundan los ejemplos de este uso:

25 Facsímil de la edición paleográfica por Don R. Menéndez Pidal, Madrid, 1961. 
«Grande duelo auien las yentes christianas» (v. 29)

"Ya lo vee el Çid que del Rey non auie gracia» (v. 50)

"Aun vea el dia que demi ayades algo» (v. 205)

"Commo sirua adoña Ximena et alas fijas que ha» (v. 384)

"Non lo saben los moros el ardiment que an» (v. 549)

«Ouo grand pesar...» (v. 959)

"Abremos esta vida mientras ploguiere al padre santo" (v. 1047)

"Quel ayades merçed siuos vala el Criador!»

«Echastes le de tierra, non ha la vuestra amor» (vv. 1324 s.).

Ejemplos de este uso podrían aducirse por docenas. Pero ya en la misma fuente los hay del uso unipersonal en que auer equivale a «existir» o "estar", y es, por tanto, intransitivo. Sólo se aducen aquí media docena, que parecen indiscutibles:
v. 1215: "Todos eran ricos quantos que alli haw.
v. 1920: «En pocas tierras a tales dos varones».
v. 3288 s.: «Quando pris a Cabra, e auos por la barba
Non y ouo rapaz que non messo su pulgada*.
v. 3455: «si ay qui responda o dize de no».
v. 3509 s.: «Hyo lo juro por sant Esidro el de Leon
Que en todas nuestras tierras non ha $\tan$ buen varon».
v. 3513 s.: «Mandastes me mouer a Babieca el corredor,
En moros ni en christianos otro tal non ha oy*.

En el v. 1215, "quantos que alli ha" equivale a "quantos que y son», fórmula ésta repetida a lo largo del poema (vv. 742, 2060, 2063, 2119, $2302,3037,3100)$, y a otras expresiones como «los otros que y son» (v. 1998), "quantos aqui son" (vv. 2033, 2561), "quantos que aqui son» (v. 2079), «los buenos que y son" (v. 3072), "Con todos sus parientes e el vando que y son" (v. 3162), en todas las cuales podría sustituirse son por ha.

En el v. 1920 elogia el Cid a Mynaya y a Pero Vermuez diciendo: «En pocas tierras a tales dos varones». ¿Cuál puede ser el sujeto tácito y vago de ese $a=h a y$ ? ¿Dios? ¿El mundo? ¿La humanidad? Parece fuera de lugar atribuir al Cid tales conceptos.

Los vv. 3288 s. reproducen asimismo palabras del Cid, dirigidas al conde don García. ¿Cuál podría ser aquí el sujeto de ouo si considerásemos rapaz como un complemento directo? ¿La ciudad de Cabra? Sobraría entonces $y=$ "en Cabra». Sería como si se dijera: "Cabra non ouo en Cabra rapaz que non messo su pulgada».

En el v. 3455, Alvarfáñez, después de mostrar ante la corte su desprecio por los infantes de Carrión, a quienes termina apostrofando: «En todas guisas tales sodes quales digo yon, concluye: ${ } \mathrm{Si}$ ay qui responda 
o dize de no / Hyo so Albarfanez pora todel meior». ¿Cuál podría ser el sujeto tácito de ay? ¿La corte? Pero $y$ equivale a «en la corte», y se diría entonces: «Si la cort ha en la cort qui responda...» ( «i la corte tiene en la corte quien me responda o me contradiga»).

Más patente aún parece el sinsentido de suponer para non ha, en los vv. 3510 y 3514, un sujeto que no sea, respectivamente, tan buen varón y otro tal. En 3510, de haber tal sujeto, sólo podría ser el propio rey Alfonso, que es el que está hablando. Pero, entonces, lo natural sería que usara la primera persona y dijera: "Que en todas nuestras tierras non he tan buen varónn. Y en el v. 3514, donde el que habla es el Cid, no se concibe cuál puede ser el sujeto tácito de ha. Si «otro tal» fuese complemento directo, sería fácil dar un sujeto expreso al verbo, pero cambiando la persona de éste: "Ni moros ni christianos otro tal non han oy" 26 .

7.1. En el s. XIV sigue predominando el valor transitivo de haber. En sólo dos páginas del Libro del cauallero et del escudero de Don Juan Manuel ${ }^{27}$ pueden verse, entre otros, los siguientes ejemplos:

«et guardauales muy bien lo que auian de los otros reys» (pág. 42, lín. 28).

"[el amor] que todos le deuian auer asi commo a su rey et a su sennor natural» (ib., lín. 30).

«et gran sabor auian las gentes del [ = de le] servir» (ib., líns. 44-45).

«Et quanto el clerigo missa cantano a mayor dignitat» (pág. 44, lín. 13).

"...fazer obras de que aya mayor mereçimiento» (ib., lín. 15).

«et este estado non puede auer ninguno [ = nadie] por si” (ib., cap. XVIII, lín. 15). «los sacramentos de sancta Eglesia an en sí cosas çiertas» (ib., lín. 17).

En todos estos ejemplos, las formas (personales) de auer se traducirían al esp. moderno por las correspondientes de tener.

26 Nótese que en los seis ejemplos está expreso un complemento locativo, representado en los vv. 3289 y 3455 por el adverbio $y$. El complemento locativo encierra de algún modo el concepto de lo que sería sujeto en la construcción personal de haber transitivo o de su equivalente moderno tener. Así, el verso

Hay en los bosques pajaros y flores

podría transformarse, sin perder nada del sentido, en este otro:

Tienen los bosques pajaros $y$ flores

o, con tono arcaizante:

Han las florestas pajaros y flores,

cuyo sujeto serían los bosques (o las florestas), complemento locativo de hay en el primer verso.

27 Obras completas $I$, edición, prólogo y notas de José ManURz Blbcua, Madrid, Gredos, 1982, págs. 42-46. 
Este significado de «tener» lo había perdido auer casi por completo a comienzos del Siglo de Oro. Garcilaso puede explicar que Noé «quiere decir no tengo"; tal explicación sería improcedente dos siglos antes. Según Juan de Valdés, «aya y ayas por tenga y tengas se dezía antiguamente, y aún lo dicen algunos, pero en muy pocas partes quadra» ${ }^{28}$. Actualmente, haber sólo conserva su antiguo valor transitivo en ciertos arcaísmos como "los que han hambre y sed de justicia» (lenguaje religioso), «los autores del crimen aún no han sido habidos» (leng. jurídico), o en alguna frase hecha, como «habida cuenta de que...». «El hecho capital en la historia de nuestro vocablo [haber] -resumen J. Corominas y J. A. Pascual ${ }^{29}$ - es el progresivo retroceso de su empleo como verbo principal, reemplazado por tener. [...] en el siglo $\mathrm{xv}$ se halla en suma decadencia [...] en el XVI apenas sobrevive el uso de aver como verbo principal en el lenguaje arcaico del Romancero».

7.2. La pérdida del valor transitivo de haber se manifiesta ya en los primeros monumentos de la lengua también en su uso como auxiliar para la formación de los tiempos compuestos. Cuando uno de estos tiempos lleva complemento directo, el participio suele concertar con el complemento. Abundan en el Poema de Mio Cid ${ }^{30}$ ejemplos como los siguientes:

De todo conducho bien los ouo bastidos (v. 68)

...sus aueres, delos que auien ganados (v. 101)

... yo XXX he ganados (v. 207)

Los vj dias de plazo passados los an (v. 306)

...la missa acabada la an (v. 366)

El agua nos an vedada... (v. 667)

Esta albergada los de myo Çid luego la an robada (v. 794)

Asos castiellos alos moros dentro los an tornados (v. 801)

Desta batalla que auemos arrancada (v. 814)

E de sus compañas, aquelas que auien dexadas! (v. 929)

Las armas auien pressas... (v. 1001) ${ }^{31}$.

28 Cit. por RAfael LAPESA, Historia de la lengua española, 9." ed. corregida y aumentada, Madrid, Gredos, 1981, pág. 399. De la sustitución de haber por tener hay al menos un ejemplo en el Poema del Cid, v. 3469: «Armas e cauallos tienen los del Campeador».

29 Diccionario Crítico Etimológico Castellano e Hispánico, vol. III, Madrid, Gredos, 1980, pág. $29 \mathrm{~b}$.

30 Ed. cit. en la n. 25.

31 Ejs. análogos en los vv. 1051, 1119, 1149, 1170, 1196, 1249, 1273, 1341, 1400, 1408 , $1433,1596,1607,1630,1725,1751,1795,1809,1819,2189,2200,2259,2422,2482,2605,2617$, $2906,2909,3062,3278,3441,3669$. A veces el participio concierta con un complemento femenino a pesar de romper una serie de rimas asonantes en $a-0$; así en 794: «an robada», 814: «auemos arrancada», 929: «auien dexadas», 1751: «an dada». Esto parece indicar la fuerza de la costumbre de concertar el participio con el complemento 
En estas y otras construcciones semejantes, auer conserva bastante de su valor transitivo, y el participio mantiene su carácter adjetival, que le hace concertar con el sustantivo. Pero en la misma fuente aparece también, aunque con menos frecuencia, el participio invariable, en género masculino, muchas veces dentro de series de versos con rima asonante en $a-o$, que puede haber influido en la forma del participio; así en:

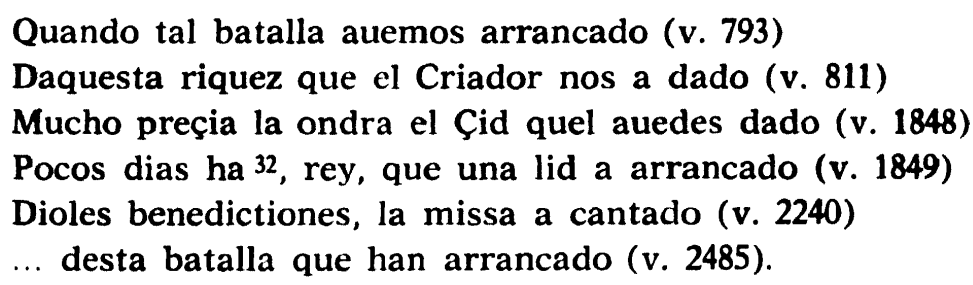

Esto parece indicio de que auer está ya perdiendo el valor transitivo, que se concentra en el verbo auxiliado. El participio, por su parte, reduce su propia entidad en favor de la forma verbal compuesta, que, al funcionar como un tiempo global, deja de concordar con el complemento.

7.3. El debilitamiento del valor transitivo de haber hace posible que pase a sustituir a ser como auxiliar de los verbos intransitivos. Estos no podían llevar complemento directo. El sustantivo o pronombre que los acompañaba inmediatamente, e. d., sin preposición, ejercía siempre la función de sujeto. Y, cuando se auxiliaban con ser, el participio auxiliado concertaba con dicho sustantivo o pronombre: «De Castiella la gentil exidos somos aca» (v. 672), "Passada es la noche, venida es la mañana / Oyda es la missa, e luego caualgauan» (vv. 1540 s.), «Entrados son a Molina» (v. 1550), "...fuera eran exidos» (v. 1629), «El dia es passado, et entrada es la noch» (v. 2061), "...que tornasse cada uno don salidos son» (v. 2112), "Venidos son a Castiella» (v. 2269), «...en Valençia son rastados» (v. 2270). Pero muy pronto se inicia la sustitución de ser por haber, permaneciendo invariable el participio: «Arribado an las naues...» (v. 1629), «...a Valençia an entrado» (v. 2247). Nótese, en cambio, que en la voz pasiva -que no admite complemento directo a pesar de ser transitivos todos los verbos que pueden tenerla- el auxiliar sigue siendo el verbo ser, y el participio auxiliado concierta siempre con el sujeto: "el niño fue visto», «la niña fue vista», «los niños fueron vistos», «las niñas fueron vistas».

de la forma compuesta del verbo y su predominio sobre el uso del participio invariable, masculino singular.

32 Nótese aqui el otro uso de haber terciopersonal, equivalente al mismo uso de hacer en expresiones de tiempo. 
7.4. De las siete acepciones de haber unipersonal que, según la $G R A E$, «se reducen a la acepción primitiva de este verbo, que es la de tener» (cfr. supra, 1.3. y n. 3), si exceptuamos la n..$^{\circ} 10$-poco frecuente y de sabor arcaico-, a juzgar por la glosa del significado de cada una que se hace en el $D R A E$, ninguna se reduce a tal acepción, que tenía valor transitivo; todos los verbos utilizados por el $D R A E$ para su glosa son intransitivos: 4. Acaecer, ocurrir, sobrevenir; 5. Verificarse, efectuarse (transitivos de suyo, pero intransitivos en la forma pronominal); 6. Ser necesario, ser conveniente; 7. Ser inútil, ser inconveniente, ser imposible; 8. Estar en alguna parte, y 9. Hallarse o existir. Antepóngase o pospóngase a cualquiera de estos verbos el pronombre indefinido algo, y se verá que funciona como auténtico sujeto; inténtese convertir en pasiva cualquiera de las oraciones resultantes ${ }^{33}$, y se verá que es imposible.

8. La debilitación de la transitividad de habere comenzó en tiempos anteriores a las lenguas románicas, probablemente ya en época indoeuropea, pues hallamos indicios de tal proceso no sólo en el lat. habere sino también en el gr. $\varepsilon_{\chi} \varepsilon\llcorner$ เ

8.1. El valor intransitivo de habere aparece ya en Plauto y más tarde en Varrón, con el significado de «morar», "vivir», "habitar», "estar»: qui Syracusis habet "que está en Siracusa", ubi nunc habet? "¿dónde está ahora?» (Plauto); in delubro, ubi aeditumus habere solet "en el santuario, donde suele estar el guardián del templo» (Varrón). Cicerón y Horacio usan ocasionalmente habere con el sentido de "hallarse», "encontrarse», «estar», «ser»: sic habemus «así estamos" («en esta situación nos encontramos»), bene habet "está bien» (Cic.); sic habet «así es» (Hor.). Estos usos proceden sin duda de la construcción reflexiva habere se, p. ej., se bene habere "encontrarse bien", «estar bien»: ut se haberent rogitans "preguntando repetidamente cómo se encontraban», se lee en Livio. (Nótese que habitare «habitar» es un frecuentativo derivado de habere, y ya en lat. tenía un valor preponderantemente intransitivo).

8.2. Algo semejante ocurre en griego con $\xi_{\chi} \chi \omega$ «tener», usado frecuentemente con adverbios de modo, significando entonces «estar 0 aha-

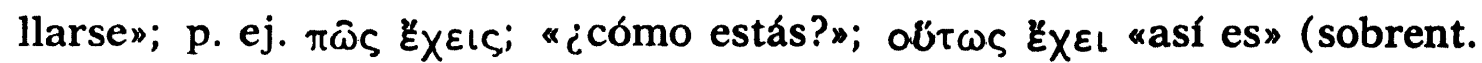
$\tau \dot{\alpha} \pi \rho \alpha ́ \gamma \mu \alpha \tau \alpha$ "las cosas"; cfr. lat. cum res ita se habeant «siendo así»,

33 Excepto las de 5., que ya serian pasivas reflejas y, mediante una leve transformación, podrían convertirse en pasivas perifrásticas: algo se efectúa / algo es efectuado por alguien; lo que era sujeto sigue, naturalmente, siéndolo. 


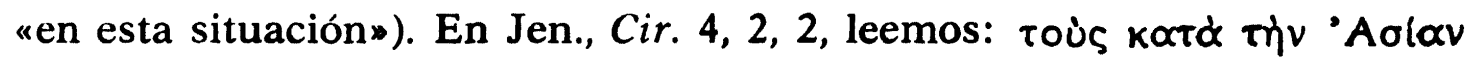
Éxovtas «a los que habitan en la zona de Asia».

8.3. Esta tendencia a la intransitividad no la muestran en lat. sólo habeo y sus derivados, sino también otros verbos. El proceso tiene como base el uso reflexivo con valor de voz media, y se lleva a cabo mediante la supresión del pronombre: se vertere "volverse", «convertirse" / vertere «id»: male res vertunt "las cosas se ponen mal». Este desarrollo se debería, según Väänänen, «al uso antiguo de asignar al participio de presente tanto la función medio-pasiva como la activa» ${ }^{34}$.

Pero en el fondo se trata de un fenómeno universal, donde la brevedad concurre a la expresividad; así, trahere "durar», Celso 2, 8, 24: si quis etiam in eo morbo diutius traxerit; coagulare "cuajar(se)», coquere *cocer» (trans. e intrans.), frangere "romper(se)" [...] mutare «cambiar» (trans. e intrans.), movere "mover» y «moverse», reficere «rehacerse, tomar la comidan: Ben. Reg.: si... fratres reficiunt sexta hora ${ }^{35}$.

8.4. La misma tendencia sigue actuando en el esp. contemporáneo. Verbos básicamente transitivos, como abrevar, adherir, confesar, entrenar, referir, se usan a veces como intransitivos. En abrevar, confesar, entrenar se llega a la intransitividad por la omisión del pron. reflexivo; en adherir y referir, dicha omisión se produce probablemente por influjo del inglés. Es sabido que en esta lengua el proceso es normal; el verbo reflexivo elide habitualmente el pronombre complemento directo: I washed "me lavé», I dressed "me vestín, He was shaving «estaba afeitándosew, etc. Estos verbos conservan, junto al uso intransitivo, el valor transitivo.

8.5. No sucedió lo mismo con haber, que, como ya vimos (supra, 7. y 7.1.), perdió muy pronto y casi por completo el valor transitivo. Pero tampoco es el suyo un caso único de este tipo de evolución semántica. Quedar (intransitivo) "permanecer, detenerse en algún sitio» procede del lat. quietare "tranquilizar», "sosegar" (transitivo). Un ejemplo típicamente medieval y más paralelo al de haber lo tenemos en fincar, del lat. figicare, frecuentativo de figere "fijar", "sujetar", del cual procede también la forma moderna hincar. Esta sólo heredó el valor transitivo, mientras que fincar tuvo en la Edad Media un uso vacilante entre el significado inicial "fijar, clavar» (transitivo) y el posterior «permanecer, quedar» (intransitivo), que perdura en el port. ficar. Se hallan ejs. del

34 Introducción al latín vulgar, ed. citada en la n. 8, págs. 205 sig.

35 Ibid.

LXIII, $1.0-2.0^{\circ}-5$ 
uso primero en Alex. 1008, 1223: fincar ojo "clavar la vista», y en Berceo, Mil. 77 a: fincar tu rodiella ${ }^{36}$, y ya antes en el Poema del Cid ${ }^{37}$ :

Finco los ynoios, de coraçon rogaua (v. 53)

Fincaua la tienda e luego descaualgaua (v. 57)

Antel Campeador doña Ximena finco los ynoios amos (v. 264)

Fincaron las tiendas... (v. 656)

...tornan tiendas a fincar (v. 1101)

Finco los ynoios ante todo el pueblo (v. 1318)

Fincaron las tiendas... (v. 1631)

...tiendas vieron fincadas (v. 1645)

Fincadas son las tiendas (v. 1657)

Delant el Campeador los ynoios fincaron (v. 1759)

Los ynoios e las manos en tierra los finco (v. 2021)

...fizo myo Çid fincar vij tablados (v. 2249)

Myo Çid finco el cobdo (v. 2296)

El que en buen ora nasco los oios le fincaua (v. 2392)

Mandan fincar la tienda yfantes de Carrion (v. 2701)

En el fincan los oios don Eluira e doña Sol (v. 2859)

Delant el rey finco los ynoios aquel Muño Gustioz (v. 2934)

Con el tiempo parece predominar el uso intransitivo, abundantemente documentado ya en el mismo poema:

Toda la quinta a myo Çid fincaua (v. 515)

En Casteion non podriemos fincar (v. 531)

Nos pagados fincados [sic por «fincamos»] (v. 854)

$Y$ ffinco en un poyo que es sobre Mont Real (v. 863)

Non lo dizen a nadi, e finco esta razon (v. 1377)

$E$ yo fincare en Valençia (v. 1470)

Yo ffincare en Valençia (v. 1472)

El uno finco con ellos e el otro torno a Albarfanez (v. 1497)

Myo Çid finco antellas (v. 1747)

...bien pueden fincar pagados (v. 1782)

E çercan el escaño e fincan sobre so señor (v. 2285)

Ca los moros... non fincaran en campo (v. 2354)

Que non y fincas ninguno, mugier nin varon (v. 2709)

Martin Antoljnez en el campo fincaua (v. 3667)

Está claro que, en frases como «Et asi fincarán omnes non tan bien commo avian mester: ca el que muestra fincará engannador, et el que aprende fincará engannado" ${ }^{38}$, el verbo lleva sujeto (omnes, el que

36 Ejemplo cit. por J. Corominas, DCELC, s. v. Hincar.

37 Ed. cit. en la n. 25.

38 Don Juan Manuel, Libro del cauallero et del escudero, ed. cit. en la n. 27, pág. 71, líns. 25-27. 
muestra, el que aprende) y atributo (non tan bien... mester, engannador, engannado), pero no puede llevar complemento directo ${ }^{39}$.

9. Para terminar, reconsideremos los argumentos de los partidarios de hay seguido de complemento directo. Estos argumentos se reducen a dos:

1. ${ }^{\circ}$ El sujeto de hay es vago e indeterminado, y su idea «se ofrece de un modo oscuro y fugaz al entendimiento, pero no tanto que no produzca efectos gramaticales, concordando con el verbo en tercera persona de singular" (Bello, supra, 1.1.). El sustantivo regido por hay es complemento directo de este verbo. "Por eso construimos el verbo en singular cuando decimos hubo toros [...] y no hubieron toros» (GRAE, supra, 1.3.). Dicho de otro modo: un sujeto plural tendría que llevar el verbo en plural; luego toros no puede ser sujeto de hay. Tal sería el corolario de la siguiente descripción del sujeto: "Frente a la definición lógicosemántica que daba la gramática tradicional, se postula la distinción del sujeto por el hecho de que es el único elemento nominal que cambia su marca de número con el verbo con el cual concuerda. He aquí una serie de tres elementos:

(1) El niño

(2) *El niño

(3) Los niños

(4) `Los niños

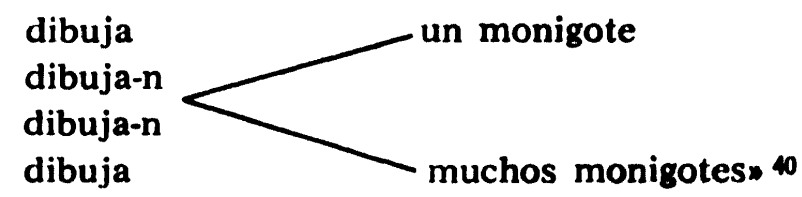

2.0) "Que la cosa cuya existencia se significa [mediante las 3.as personas de singular de haber] está en acusativo, lo prueba la necesidad del caso complementario de acusativo cuando la representamos con el pronombre él. [...] Si el impersonal haber significara de suyo existir, sería la mayor de todas las anomalías poner las cosas existentes en acusativo» (Bello, supra, 1.1.). Por eso, "cuando se nos pregunta: ¿hubo heladas?, contestamos: las hubo, empleando la forma del pronombre que sabemos es de acusativo»(GRAE, supra, 1.3.).

9.1. Al primer argumento puede contestarse:

$\left.1 .^{\circ}\right)$ Es cierto que normalmente el verbo concierta en número con el sujeto. Pero la anomalía de la discordancia es fenómeno común a

39 Sin embargo, el valor intransitivo de fincar sólo se conserva hoy, probablemente como residuo del lenguaje jurídico, en la acepción de 'establecerse en un lugar' adquiriendo en él bienes inmuebles o fincas. La forma moderna, con $h$ - en lugar de $f-$, tiene valor transitivo.

40 Juan Alcina Franck y José Manuei. Blecua, Gramática espafiola, Barcelona, Ariel, 1975, pág. 853. 
otras lenguas. En griego hallamos construcciones con el verbo en singular y el sujeto en plural; en las gramáticas escolares suele ejemplifi-

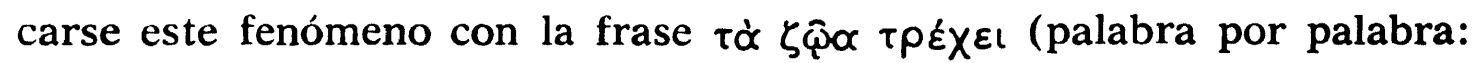
"los animales corre»), donde el artículo y el sustantivo son plurales neutros, y el verbo está en $3 .^{\mathrm{a}}$ pers. singular. En griego y en latín se daba también el fenómeno inverso: sujeto en singular con el verbo en

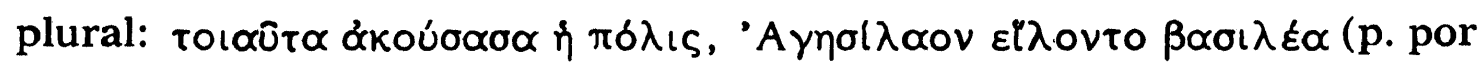
p.: "Habiendo oído estas cosas la ciudad, eligieron rey a Agesilao»), To

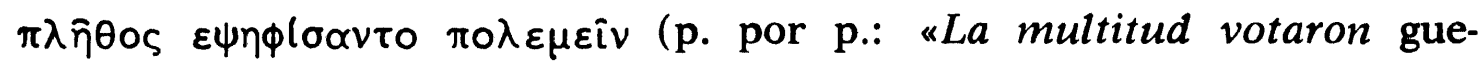
rrear»); Multitudo, pars procurrit in vias, pars in vestibulis stat, pars e tectis fenestrisque prospectant et quid rei sit rogitant (p. por p.: «la multitud, parte sale corriendo a las calles, parte permanece estacionada en los portales, parte miran desde los techos y ventanas y preguntan qué sucede»); civitati persuasit ut e finibus suis exirent (p. por p.: «persuadió al pueblo a que salieran de su territorio»). Según J. Marouzeau ${ }^{41}$, en francés se dice casi indiferentemente: "Une foule de gens se précipita o se précipitèrent».

En todos estos casos, la razón de la discordancia numérica está en el carácter colectivo de los sujetos, que hace posible separar el aspecto lógico-semántico del aspecto morfológico-sintáctico, puramente gramatical. No se debe a esto la discordancia numérica de hay + sujeto en plural. Pero, aunque en ellos la razón sea otra, los ejemplos citados demuestran que es posible este tipo de anomalía linguística.

Otro caso de discordancia numérica entre el sujeto y el verbo, y precisamente con el verbo en singular y el sujeto en plural, se da en verbos que podríamos llamar anquilosados. Esta anquilosis verbal se produce al menos por tres motivos: a) porque un verbo sólo se usa con un valor determinado en alguna de sus formas, perdiendo casi por completo su calidad verbal y pasando a la categoría de las palabras invariables; b) en sentido inverso, porque una palabra invariable inicia su transformación en verbo y luego se detiene antes de alcanzar la meta, y c) porque un verbo normal pierde la mayoría de sus formas, limitándose, p. ej., a usar las 3.as personas de singular y las formas impersonales.

Tenemos un caso de $a$ ) en el lat. age, 2." pers. singular del imperativo presente de ago, que, a pesar de tener la forma correspondiente de plural, agite, se usaba en la época clásica, con valor casi interjeccional, también para dirigirse a varios: age nunc iter... comparate; age vero considerate (ambos ejs. en Cicerón). Sucede aproximadamente lo mismo con el fr. voici, voild, considerados actualmente como preposiciones,

41 Précis de stylistique française, Paris, Masson, 1946, pág. 120. 
pero procedentes de vois, $2 .^{\mathrm{a}}$ pers. singular del imper. pres. de voir «ver» y de los adv. ci «aquí» y là "allí». El fr. ant. conservaba la independencia de ambos términos y ponía el primero en plural cuando el hablante se dirigía a varias personas: vez me ci, vez le ci (=me voici, le voici: «heme aquí, helo aquí»), 1080 Chanson de Roland, cit. por el GLLF, pág. 6528 a. Algo semejante ocurre con los participios esp. excepto y salvo, que, al perder su valor verbal y convertirse en preposiciones, dejaron de concertar en número con los sustantivos correspondientes: «Vinieron todos, excepto tus amigos»; "Se marcharon todas, excepto mis amigas».

Un ejemplo de anquilosamiento del tipo $b$ ), que sigue el camino inverso, lo tenemos en el frustrado avance de he hacia la condición de verbo. Sabemos que su origen no es verbal, sino adverbial ${ }^{42}$. Pero

en el período renacentista se percibió he como un verbo en imperativo, y de ahí que se le diese un plural heis, empleado por Timoneda y Lope, o hes [...], empleado por J. del Encina y por Salazar ${ }^{43}$.

He se sintió, en efecto, como $2 .{ }^{a}$ pers. sing. del imper. pres. de haber con valor transitivo, como se demuestra por el hecho de haberle dado un complemento pronominal en acusativo: "helo aquí», "hela aquí", helos aquí», "helas aquí" ${ }^{44}$. Que se siente aún como un verbo y no como un adverbio se manifiesta también en el hecho de que he se construya normalmente con el adverbio aqui, a veces con otra expresión de valor adverbial de sentido igualmente locativo: «Helo, helo por do viene». En la lengua actual se usa casi exclusivamente en expresiones como "he aquí un ejemplo", "he aquí lo que piensa sobre esto X.X.". Si he tuviera valor de adverbio locativo, la adición de aqui sería una redundancia incomprensible. Ahora bien, siendo usado y entendido como $2 .^{a}$ pers. sing. del imper. pres. de haber, he puede dirigirse indistintamente a un solo destinatario (sujeto del imperativo) o a varios. La razón es que el valor real de he, por el anquilosamiento de esta forma, queda a medio camino entre el adverbio originario y el verbo, con algunas características de

42 Sobre la etimología y los usos de he, cfr. J. Corominas / J. A. Pascual, DCECH, vol. III, págs. 334-35.

43 Corominas / Pascual, ibid., pág. 335.

44 He aqui se usa habitualmente para traducir el adv. lat. ecce. Una prueba adicional de que he se siente como verbo transitivo es que, cuando lleva complemento de persona, se antepone a éste la preposición a (cfr. infra, 9.2.). Las palabras de la Vulgata, Jn. XIX 4, 5: Ecce homo! suelen traducirse «jHe aquí al hombre!». Así en el Evangelio de N. S. Jesucristo, armonizado y ordenado cronológicamente en español, inglés, francés y alemán por Dionisio Yubero, Madrid, Epesa, 1972, pág. 84. En nota al pie de la página, las palabras «He aquí al hombre» se glosan reiteradamente con la expresión «Ahí tenéis al hombre», que el traductor considera sin duda equivalente. La versión francesa, pág. 254, dice: "Voilà l'homme". 
éste, pero careciendo de las demás: puede llevar, como hemos visto, complemento directo y complemento circunstancial; a veces, también complemento indirecto: "Hete aquí que estalla de pronto una gran tormenta»; pero no tiene las múltiples formas de una conjugación normal.

El verbo haber con valor intransitivo equivalente al de estar o existir sufrió el anquilosamiento del tipo $c$ ), limitando su uso a las formas impersonales y a las $3 . .^{\text {as }}$ personas de singular. Su función es, en éstas, la de un elemento presentador, como lo es también la de voici y la del he sentido como imperativo, con la diferencia de que voici y he, relacionados con verbos transitivos, son presentadores de complementos directos, mientras que las formas impersonales y las 3.as personas de sing. de haber intransitivo, precisamente por ser intransitivas, no pueden presentar tales complementos, sino que presentan su propio sujeto.

2. ${ }^{\circ}$ ¿Por qué ese supuesto "sujeto vago» de hay, había, etc., tendría que ser siempre singular? ¿Sólo porque el verbo está en singular? Pero, si suponemos que esas terceras personas de singular siguen teniendo en el fondo valor transitivo, ¿por qué habían de usarse ellas solas y no las demás personas del mismo verbo? $\mathrm{Si}$, en efecto, atribuimos a haber valor transitivo reducible a la acepción primitiva de este verbo, equivalente a tener, ¿qué vago sujeto singular podríamos asignar a hubo en la frase «En torno a esta ciudad hubo un gran combate»? ¿Quién tuvo ese gran combate? Los combates, grandes o pequeños, suponen siempre al menos dos combatientes; éstos son los que tienen el combate. De manera que la frase correcta sería en tal caso: «En torno a esta ciudad hubieron un gran combate». $Y$ algo parecido sucedería en esta otra frase: "Entre nosotros hay confianza». ¿Quién tiene esa confianza? Evidentemente, nosotros. Luego el sujeto de hay sería plural, y en plural debería estar el verbo supuestamente correcto: «Entre nosotros habemos confianza». Un último ejemplo. A la entrada de cierta casa de comidas regentada por dos hermanos, un letrero escrito con tiza en una pizarra avisa a los clientes durante la temporada de pesca: HAY TRUCHAS. Cuando éstas escasean, si las hay algún día, el letrero dice: HOY TENEMOS TRUCHAS ${ }^{45}$. La equivalencia es, pues, hay = tenemos. El sujeto de tenemos es, indudablemente, nosotros, y, de admitir el valor transitivo de haber en la formulación del anuncio, la forma correcta de éste pediría la concordancia del verbo con el sujeto: HOY HABEMOS TRUCHAS. Así podría decirse sin duda en el siglo xiv.

45 La variación se debe probablemente a cierto instinto estilístico de los duenos del establecimiento, que los mueve a evitar la redacción, correcta pero cacofónica, HOY HAY TRUCHAS. 
9.2. El segundo argumento, que se apoya en el uso del acusativo del pronombre de 3. ${ }^{\mathrm{a}}$ persona: $l o, l a, l o s, l a s$, cuando éste representa al nombre que acompaña inmediatamente a las $3 .^{\text {as }}$ personas de singular de haber, y de aquí deduce que tal nombre es complemento directo, tiene, sin duda, fuerza no desdeñable. Dichas formas pronominales no se usan con verbos como existir o estar. A la pregunta " $i$ Existen hombres en Marte?» no se puede contestar: "No los existen». Pero, si se pregunta: "¿Hay hombres en Marte?», sería una respuesta gramaticalmente correcta: "No los hay", del mismo modo que a la pregunta: "¿Has visto hombres con cinco piernas?" puede contestarse correctamente: "No los he visto». Esto parece demostrar que hay tiene valor transitivo lo mismo que he visto. Ese valor transitivo justificaría el uso del acusativo los, sintácticamente un complemento directo.

Pero el uso del acusativo pronominal con hay, habia, etc., puede explicarse como un resto fosilizado del uso primitivo de haber fundamentalmente transitivo y equivalente al actual tener. En los primeros tiempos del castellano se usaban con cualquier persona de auer (no sólo con las 3.as de singular) las formas pronominales de acusativo, porque representaban a nombres cuya función sintáctica era la de complemento directo de un verbo transitivo, lo mismo que usariamos hoy esas formas pronominales con cualquier persona de tener: «lo tengo», «la tenías», "los tuvo", "las tendremos". Al perder casi por completo haber su valor transitivo y reducirse, como intransitivo, a las terceras personas de singular y a las formas impcrsonales, el uso de lo, la, los, las con estas formas del verbo quedaría incrustado en su funcionamiento como anomalía sintáctica. Ayudaría a la creación y conservación de esta anomalía el coincidir las formas de acusativo del pronombre de 3. ${ }^{2}$ persona con cuatro de las formas del artículo determinado (neutro y femenino sing., masculino y femenino plural), que se usan ante sustantivos o elementos sustantivados tanto en función de sujeto como de complemento directo: "lo tuyo es bueno», «la tuya es buena», "los míos son buenos», «las mías son buenas»; "quiero lo mío", "quiero la tuya", "quiero los míos», "quiero las mías". Hay incluso otras construcciones del artículo que se hallan más próximas a su valor originario de pronombre, cuando el artículo se usa omitiendo o sobrentendiendo el sustantivo o elemento sustantivado al que determinaría: "lo de arriba", "la de seda», «los de tacón», "la de color rojo». Todas estas expresiones pueden funcionar como sujeto o como complemento directo, según sea el verbo con el que se construyan.

Pero es preciso admitir que la explicación precedente no es más que una hipótesis. 
Hay, en cambio, un argumento que contrarresta la fuerza del que se basa en el uso de lo, la, los, las con las formas terciopersonales e impersonales de haber. Se trata del argumento ya utilizado por Martínez Amador y que hemos esbozado en 2.1.4. No se puede considerar acusativo, e. d., complemento directo, el sustantivo o elemento sustantivado que acompaña a las $3 .^{\text {as }}$ pers. de singular de haber o a sus formas impersonales porque no se le puede anteponer la preposición a cuando se refiere a una persona. Se dice, p. ej., «No hay Carlos que valga», «No hay quien le aguante», "No hay nadie», pero seria incorrecto decir: «No hay a Carlos que valga», "No hay a quien le aguante», «No hay a nadie». Se diría, en cambio, "No conozco a Carlos», "Admiro a quien le aguante», "No veo a nadie". El Esbozo de una nueva gramática de la lengua española, 3.20.8 a) y $b$ ), dice que el relativo generalizador quien «se refiere únicamente a personas o cosas personificadas», y pone como ejemplo en que este pronombre es sujeto: Quien canta sus males espanta. Pues bien, este dicho popular puede transformarse así: Hay quien(es) canta( $n$ ) para espantar sus males, o bien: Conozco a quien(es) canta(n) para espantar sus males. En la segunda formulación ponemos a ante quien(es) porque representa al complemento directo de conozco, aunque sea al mismo tiempo sujeto de canta(n). Pero sería incorrecto decir Hay a quien(es) canta(n) para espantar sus males, porque quien(es) representa aquí al sujeto de hay, verbo intransitivo, que, por consiguiente, no puede tener complemento directo. Véase, como último ejemplo, el siguiente fragmento de romance:
ofende a quienes la admiran y admira a quienes la ofenden, aborrece a quienes la aman y ama a quienes la aborrecen.

En los cuatro versos, quienes lleva antepuesta la preposición a porque en todos ellos es complemento directo de un verbo transitivo: ofende, admira, aborrece, ama. El conjunto de los cuatro versos implica que hay quienes la admiran y hay quienes la ofenden, hay quienes la aman y hay quienes la aborrecen; implicaciones cuya formulación sería no sólo incorrecta sino también incomprensible si, viendo en hay un verbo transitivo, antepusiéramos a quienes la preposición que llevan los complementos directos de contenido personal o personificado: Hay a quienes la admiran, hay a quienes la ofenden, hay a quienes la aman, hay a quienes la aborrecen.

10. El hecho de que una gran mayoría de los hispanohablantes, sobre todo entre los hispanoamericanos, conviertan en personales las for- 
mas unipersonales de haber para concertarlas con el sustantivo acompañante cuando está en plural -hubieron grandes fiestas, habian tres hombres en la plaza; incluso en la 1." pers.: habiamos (alli) muchos por estábamos alli muchos o éramos muchos - no es válido como prueba de que el sustantivo o elemento sustantivado que acompaña inmediatamente a hay, habia, etc., sea sujeto. La norma linguiística del español rechaza todavía esa concordancia, que los hablantes linguiísticamente cultos consideran vulgarismo. Pero también la gran mayoría, por no decir casi la totalidad, de estos hablantes conocedores y practicantes de la norma lingüística sienten como sujeto -aunque no concierte en número con el verbo- el sustantivo o elemento sustantivado de referencia. Sólo entre los gramáticos más atentos a la primitiva significación de haber que a su evolución sintáctica hay quienes sostienen la opinión contraria.

\section{APENDICE}

Escrito ya este artículo, mi amigo José Polo, siempre dispuesto a compartir generosamente su gran saber bibliográfico, me comunica la existencia de varios trabajos sobre esta materia. Los dos más recientes son el de J. Luque Moreno, «En torno al sintagma 'haber impersonal + sustantivo' y sus orígenes latinos», Revista Española de Lingüística, enero-junio de 1978, 125-147, y el de Jesús Moreno Bernal, «El uso impersonal de 'haber' en un texto del siglo xiIn", Boletin de la Real Academia Española, mayo-agosto de 1978, 281-291.

Luque Moreno, cuya postura es muy semejante a la mía, reconoce que los graináticos españoles se muestran casi unánimes al analizar el sintagma «hay + sustantivo" como constituido por un verbo impersonal más un complemento directo. Pero él insiste en el valor existencial de haber impersonal, que res más que evidente en español ya desde antiguow. Este valor existencial se remonta al del verbo latino habere, ampliamente documentado por Luque Moreno, que aduce numerosos ejemplos demostrativos de la concomitancia semántica entre habere y esse. En la pág. 144, apartado 4.3.3., resume con claridad y exactitud el problema planteado por la frecuencia de la construcción «habet impersonal + acusativo»: «si no es anómalo ni el contenido semántico existencial de habeo ni tampoco su empleo como impersonal, queda claro que la anomalía del sintagma 'habeo impersonal + Ac.' reside en la presencia de dicho acusativo, ya que parece tratarse de un complemento directo unido a un verbo de estado y, por tanto, intransitivow. Este punto de vista es similar al adoptado por mí en el segundo párrafo de 9.2.

Luque Moreno ve el origen de este fenómeno en «una contaminación de dos construcciones del verbo habeo: la construcción con acusativo, propia de dicho verbo en cuanto transitivo, y la construcción como intransitivo, también propia de habeo en cuanto verbo de estado. De la contaminación de habet (= posesión) + CD y habet impersonal (= existencia) surge este sintagma híbrido, habet impersonal (= existencia) + Acusativo" (pág. 145). Enumera varios factores que pueden haber contribuido a la tolerancia de esta construcción de suyo estridente; el más impor- 
tante fue sin duda "la decadencia de la flexión nominal en latín tardío y en concreto el creciente intercambio de formas entre nominativo $\mathbf{y}$ acusativo, $\mathbf{y}$ el establecimiento de este último como caso universal» (págs. 145-46). Y concluye: "Así, pues, el sustantivo que acompaña al verbo habere en estas expresiones [...] no pudo ni debió tener nunca categoría de auténtico complemento directo $[\ldots] \mathrm{Si}$, a pesar de todo ello, se mantuvo la forma de acusativo, fue porque se constituyó una especie de sintagma fosilizado en el que dicha forma pervivió por inercia» (pág. 146). Esta explicación coincide con la que yo doy en el párrafo segundo de 9.2. para el uso, en castellano, del acusativo pronominal con las formas impersonales de haber.

J. Moreno Bernal, sin plantear expresamente el problema de si el sustantivo que acompaña a las formas impersonales de haber es sujeto o complemento directo, adopta una postura ecléctica. "Para expresar la idea de existencia -dice en 2.2.1., pág. 284-, el castellano, desde la Edad Media hasta hoy, ha preferido el verbo haber, según la fórmula que hemos visto en latín vulgar, es decir, utilizando sólo la tercera persona del singular con el acusativo como sujeto lógico del que se dice que existe, aunque tal existencia no se predique de un modo absoluto, sino ligada casi siempre a una localización» (la cursiva es mía). Pero en castellano, salvo en los restos de declinación pronominal, no hay nominativo ni acusativo; simplemente existen funciones sintácticas como las que estos casos desempeñaban en latín, especialmente las de sujeto y complemento directo.

Para nuestro tema, lo más interesante del artículo de Moreno Bernal son los ejemplos. Entre éstos hay dos pasajes latinos cuya traducción pone de manifiesto la equivalencia de «est + sustantivo en nominativo» y $\propto a$ + sustantivo»:

Prov. 19, 2: "ubi non est scientia animae, non est bonum» "ó non á saber del alma, no dá bien"

Prov. 31, 4: «nullum secretum est ubi regnat ebrietas" «no á poridat ninguna ó befdez regna» (pág. 287; cursiva mfa).

Allí mismo aparece otro texto, de $J n .14,2$ :

aen la casa de mio padre muchas moranças $y$ d’

que es traducción de la Vulgata:

"In domo Patris mei mansiones multae sunt" (cursiva mía).

Los tres pasajes pretenden reproducir el original latino palabra por palabra. Cuando se tradujeron estaba vivo el uso del verbo ser con el mismo valor que aquí se atribuye a haber. Moreno Bernal (pág. 283) cita media docena de ejemplos del mismo manuscrito; sólo transcribo uno que tiene el sujeto en plural:

«seys cosas son que aborrece Dios» (Prov. 6, 16).

En el pasaje correspondiente de la Vulgata se lee:

«Sex sunt quae odit Dominus».

El traductor conocía, pues, y usaba las dos posibilidades, que para él eran equivalentes. ¿Sería razonable pensar que cuando traduce Sex sunt por «seys cosas son» considera «cosas" como sujeto, y cuando traduce mansiones multae sunt por «muchas moranças $\dot{y} a$ » ve en «muchas moranças» un complemento directo? 
La teoría del núcleo disociado que el propio J. Polo toma de Tesnière y aplica a sintagmas como «habet libros", "hay libros" (Casuística gramatical», Boletin de Filología Española, Madrid, 30-31 (1969), pág. 55, n. 7, y Las oraciones condicionales en español. Ensayo de teoría gramatical, Univ. de Granada, 1971, pág. 101, n. 30) podría explicar a lo sumo el sintagma latino, donde está claro el morfema de acusativo, del que se disociaría el semantema (pasando de «complemento directo» a «sujeto lógico»), pero no explica el sintagma español, donde «libros» no tiene morfema de acusativo ni puede, por tanto, sugerir el semantema "complemento directo".

\section{ADICION FINAL}

Compuesto y ajustado ya este artículo, mi amigo Martín de Riquer me ha regalado su excelente edición bilinguie de la Chanson de Roland. En su texto francés aparecen formas impersonales de avoir acompañadas por nombres en caso régimen, pero también, a veces, en nominativo. En un pasaje sucede lo que ya vimos arriba, al final de 3.3.5. $k$ ), en la Vie de saint Alexis; el nominativo y el caso régimen aparecen en dos versos seguidos, 909 y 910 , con la misma función sintáctica:

Uns almaçurs i ad de Moriane, n'ad plus felun en la tere d'Espaigne.

( «Hay allí un almanzor de Moriana: no hay otro más pérfido en la tierra de Españax, trad. M. de Riquer).

El caso régimen se usa ya entonces (últimos años del s. XI) incluso con formas del verbo être, cuando el sustantivo que las acompaña sólo puede ejercer la función de sujeto:

$$
\begin{aligned}
& \text { v. 1213: Un duc i est, si ad num Falsaron } \\
& \text { ( } \text { Hay allí un duque; se llama Falsarón»). } \\
& \text { v. 1519: D'altre part est un paien, Valdabrun, } \\
& \text { («En otro lado hay un pagano, Valdabrún,»). } \\
& \text { v. 1570: De l'altre part est un paien, Grandonies, } \\
& \text { ( } \text { (En otro lado hay un pagano, Grandonie,»). }
\end{aligned}
$$

Esto demuestra que los nombres que llevan el caso régimen pueden ejercer la función de sujeto. $Y$ el hecho de que a veces vayan en nominativo nombres que acompañan a formas impersonales de avoir prueba que la función sintáctica atribuida a tales nombres era la de sujeto.

\section{Valentín Garcfa Yebra}

